\title{
Metabolic and evolutionary responses of Clostridium thermocellum to genetic interventions aimed at improving ethanol production
}

\author{
Evert K. Holwerda ${ }^{1,3^{*}}$ (D) Daniel G. Olson ${ }^{1,3^{*}}$, Natalie M. Ruppertsberger ${ }^{1}$, David M. Stevenson ${ }^{2,3}$,
}

Sean J. L. Murphy ${ }^{1}$, Marybeth I. Maloney ${ }^{1,3}$, Anthony A. Lanahan 1,3, Daniel Amador-Noguez ${ }^{2,3}$ and Lee R. Lynd ${ }^{1,3}$

\begin{abstract}
Background: Engineering efforts targeted at increasing ethanol by modifying the central fermentative metabolism of Clostridium thermocellum have been variably successful. Here, we aim to understand this variation by a multifaceted approach including genomic and transcriptomic analysis combined with chemostat cultivation and high solids cellulose fermentation. Three strain lineages comprising 16 strains total were examined. Two strain lineages in which genes involved in pathways leading to organic acids and/or sporulation had been knocked out resulted in four end-strains after adaptive laboratory evolution (ALE). A third strain lineage recapitulated mutations involving adhE that occurred spontaneously in some of the engineered strains.
\end{abstract}

Results: Contrary to lactate dehydrogenase, deleting phosphotransacetylase (pta, acetate) negatively affected steady-state biomass concentration and caused increased extracellular levels of free amino acids and pyruvate, while no increase in ethanol was detected. Adaptive laboratory evolution (ALE) improved growth and shifted elevated levels of amino acids and pyruvate towards ethanol, but not for all strain lineages. Three out of four end-strains produced ethanol at higher yield, and one did not. The occurrence of a mutation in the adhE gene, expanding its nicotinamidecofactor compatibility, enabled two end-strains to produce more ethanol. A disruption in the hfsB hydrogenase is likely the reason why a third end-strain was able to make more ethanol. RNAseq analysis showed that the distribution of fermentation products was generally not regulated at the transcript level. At $120 \mathrm{~g} / \mathrm{L}$ cellulose loadings, deletions of spoOA, Idh and pta and adaptive evolution did not negatively influence cellulose solubilization and utilization capabilities. Strains with a disruption in $h f s B$ or a mutation in adhE produced more ethanol, isobutanol and 2,3-butanediol under these conditions and the highest isobutanol and ethanol titers reached were 5.1 and $29.9 \mathrm{~g} / \mathrm{L}$, respectively.

Conclusions: Modifications in the organic acid fermentative pathways in Clostridium thermocellum caused an increase in extracellular pyruvate and free amino acids. Adaptive laboratory evolution led to improved growth, and an increase in ethanol yield and production due a mutation in adhE or a disruption in $h f s B$. Strains with deletions in $/ d h$

\footnotetext{
*Correspondence: evert.k.holwerda@dartmouth.edu;

daniel.g.olson@dartmouth.edu

${ }^{\dagger}$ Evert K. Holwerda and Daniel G. Olson contributed equally to this work

${ }^{1}$ Thayer School of Engineering, Dartmouth College, Hanover, NH 03755, USA

Full list of author information is available at the end of the article
}

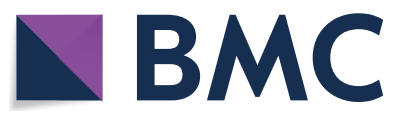

(c) The Author(s) 2020. This article is licensed under a Creative Commons Attribution 4.0 International License, which permits use, sharing, adaptation, distribution and reproduction in any medium or format, as long as you give appropriate credit to the original author(s) and the source, provide a link to the Creative Commons licence, and indicate if changes were made. The images or other third party material in this article are included in the article's Creative Commons licence, unless indicated otherwise in a credit line to the material. If material is not included in the article's Creative Commons licence and your intended use is not permitted by statutory regulation or exceeds the permitted use, you will need to obtain permission directly from the copyright holder. To view a copy of this licence, visit http://creativeco mmons.org/licenses/by/4.0/. The Creative Commons Public Domain Dedication waiver (http://creativecommons.org/publicdomain/ zero/1.0/) applies to the data made available in this article, unless otherwise stated in a credit line to the data. 
and pta pathways and subjected to ALE demonstrated undiminished cellulolytic capabilities when cultured on high cellulose loadings.

Keywords: Clostridium thermocellum, Adaptive laboratory evolution, Ethanol, Isobutanol, Cellulose utilization, Chemostat cultivation, Amino acid secretion, adhE, hfsB

\section{Background}

Metabolic engineering may be idealized as a 3-step process involving quantitative analysis of metabolism, genetic interventions aimed at achieving a desired result, and experimentally validating that the result has been achieved. In practice, genetic interventions often lead to responses other than those targeted and/or induce new selective pressures, which cause the host strain to evolve. Such induced evolution sometimes enhances performance in desired ways-e.g., when a kinetic bottleneck is spontaneously relieved as a result of a mutation-and sometimes it diminishes performance. Understanding metabolic and evolutionary responses to genetic interventions is an instructive and often necessary part of the design-build-test cycle of metabolic engineering [1]. Engineering thermophilic bacteria to produce ethanol provides illustrative examples of such responses, and is considered here.

The anaerobic thermophilic bacterium Clostridium thermocellum is a promising candidate for the conversion of lignocellulosic feedstocks to biofuels due to its native ability to solubilize cellulose [2-4]. A major impediment to commercialization is the low ethanol yield of the wildtype organism, typically $12-34 \%$ of the maximum theoretical [5]. Aiming to replicate the success realized with the non-cellulolytic hemicellulose-fermenting thermophile Thermoanaerobacterium saccharolyticum [6, 7], initial metabolic engineering efforts aimed at increasing ethanol yield in C. thermocellum focused on deleting pathways for carbon flux to lactate and acetate. Prominent examples of this approach are described in the papers of Argyros et al. [8] and van der Veen et al. [9]. In both studies, started with the same parent stain (LL345), pathway disruption did not immediately result in changes in ethanol yield, and adaptive laboratory evolution (ALE) was used to give the microorganisms a chance to adjust their metabolism in response to genetic interventions. Whereas ALE resulted in substantially increased ethanol yield in the case of a strain engineered by Argyros et al., it resulted in higher yield of amino acids (and not ethanol) in the end-strain described in van der Veen et al.

In this paper, we aimed to identify the mechanisms underlying the divergent ethanol production phenotypes of the lineages described in Argyros et al. and in van der Veen et al. to evaluate the role and impact of ALE on engineered strains, and to evaluate the extent to which engineering to increase product yield impacts cellulose fermentation capability. We applied an approach that was intended to provide us with multiple types of information; whole-genome sequencing, RNAseq and it included three different cultivation approaches each with different cultivation related fermentation data.

\section{Results and discussion}

\section{Strain lineages and analysis}

Starting with C. thermocellum strain DSM1313, the three strain lineages discussed here were developed either at Mascoma Corporation or at the Lynd laboratory by a combination of targeted genetic interventions and adaptive laboratory evolution (ALE) as described in "Methods" section (the strain developing process as such is not part of the effort described here and can be found elsewhere). The lineages of the strains studied are presented in Fig. 1. Strain LL345 was developed from wild-type C. thermocellum (DSM 1313) by deleting the $h p t$ gene, thereby allowing counter-selection using $8 \mathrm{AZH}$ (8-azahypoxanthine) useful for making unmarked genetic modifications. No change in the distribution of fermentation products was observed upon deletion of the $h p t$ gene. In lineage 1, the genes for lactate and acetate production were deleted and the strains were evolved for faster growth using a $\mathrm{pH}$ auxostat (strain LL1011) or serial transfer (strain LL1043). In lineage 2, the spo0A gene was deleted to disrupt sporulation [10], then the genes for lactate and acetate production were deleted, and strains were evolved for faster growth using a $\mathrm{pH}$ auxostat (strain LL374) or chemostat (strain LL375). Lineage 3 involved mutations in the $a d h E$ gene; wild-type adhE was deleted from LL345 resulting in strain LL1111. The wild-type gene was reintroduced in strain LL1160, and a D494G mutant adhE was reintroduced in strain LL1161. Lineage 3 also contains a mutation in the $l d h$ gene $\left(\mathrm{ldh}^{\mathrm{S} 161 \mathrm{R}}\right)$ that appeared during the creation of strain LL1111 from LL345 as discussed in Lo et al. [11].

All strains were whole-genome sequenced and tested for growth by microplate assay (see Fig. 1). All but strain LL1111 were grown in chemostats on $5 \mathrm{~g} / \mathrm{L}$ cellobiose where data for fermentation products and biomass concentration were collected and sampled for RNAseq. Finally, four strains that underwent ALE were cultivated on $120 \mathrm{~g} / \mathrm{L}$ cellulose where the exometabolome was 

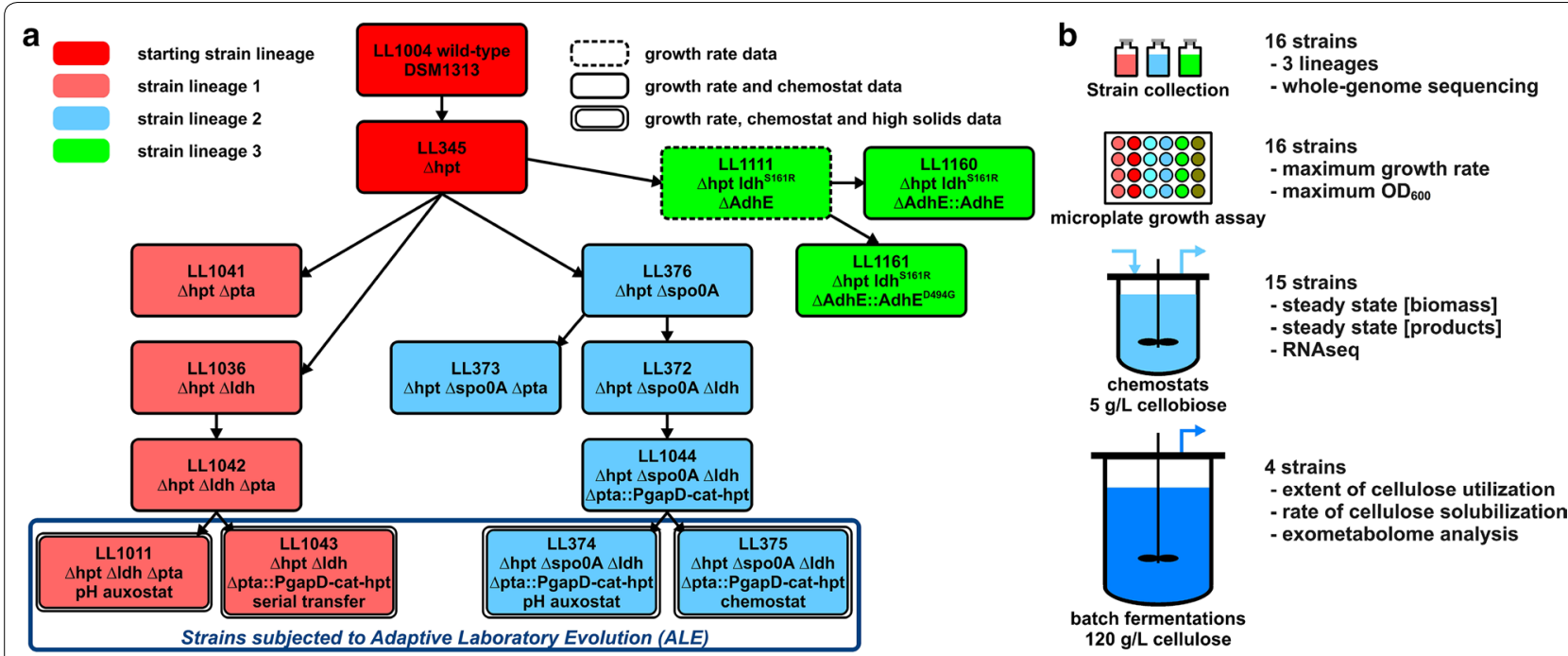

Fig. 1 Overview of the strain lineages and data associated with each strain (a) and overview of the research approach and data analysis in this paper (b). A total of 16 strains were analyzed, covering three different lineages. For each stage of the analysis different data sets were collected. Four strains (LL1011, LL1043, LL374 and LL375) have been subjected to Adaptive Laboratory Evolution, as indicated in the figure. For description of the strain, the adaptation, data generation and analysis see "Methods" section

sampled over time and data for cellulose solubilization were collected.

\section{Growth rate measurements}

Prior to characterizing growth in chemostats or under high cellulose loadings, all strains were cultured in microplates on a plate reader to determine maximum growth rate $\left(\mu_{\max }\right)$ and biomass formation as measured by $\mathrm{OD}_{600}$ (Fig. 2). In general, strains exhibiting a higher maximum $\mathrm{OD}_{600}$ also exhibited a higher $\mu_{\max }$. The factor that showed the biggest influence on both variables was the deletion of the pta gene. Deleting the pta gene had a significant negative effect on both the growth rate as well as the maximum OD as measured under batch conditions in the microplate. However, within the group of pta deletion strains, the evolved strains (LL374, LL375, LL1011 and LL1043) exhibited an improvement in growth rate after adaptation. To understand the effect of $p t a$ deletions on fermentation behavior, without the confounding effect of growth rate, we performed steady-state chemostat fermentations.

\section{Chemostat cultivation and changes in metabolic flux}

To ensure the medium was able to support growth in chemostats at a $D=0.1 \mathrm{~h}^{-1}$, and that the culture was carbon limited, wild-type C. thermocellum (LL1004) was cultured at 5 different cellobiose concentrations and sampled at steady state. Figure 3 shows a linear relation between cell concentration and carbohydrate loading. Cell concentration is expressed in terms of pellet carbon and nitrogen, which are linearly related to cellobiose utilized and to each other at a ratio of $3.35 \mathrm{~g}$ carbon/g nitrogen. The fermentation end-products ethanol, acetate, formate and lactate also are linearly correlated with substrate utilized, which indicates there is no limitation other than carbon from cellobiose.

To understand the effect of the targeted mutations and subsequent adaptation on fermentation behavior, 15 strains were grown in chemostats under carbonlimiting conditions on $5 \mathrm{~g} / \mathrm{L}$ cellobiose at a residence time (RT) of $10 \mathrm{~h}$ (dilution rate of $0.1 \mathrm{~h}^{-1}$ ). Steady state was verified by on-line in situ OD measurements, and the chemostats were sampled after $\geq 4$ residence times and again after $\geq 7$ residence times for at least duplicate, independently inoculated chemostats. Samples were analyzed for cellular biomass and major fermentation products (lactate, acetate, formate and ethanol) as well as pyruvate and free amino acids. The hydrogen concentration in the headspace was also determined and samples were checked for presence of intermediate metabolites like fumarate and malate as well as isobutanol and pyroglutamate. Non-normalized data can be found in Additional file 1: Table S1.

Measured dilution rates ranged from $0.092 \mathrm{~h}^{-1}$ (LL375) to $0.109 \mathrm{~h}^{-1}$ (LL1036). The measured substrate concentration in the feed ranged from 4.69 to $4.88 \mathrm{~g} / \mathrm{L}$ (see also Additional file 1: Table S1). Figure 4 shows 6 panels representing steady-state production levels of acetate (panel a), pyruvate (panel b), hydrogen (panel c), amino acids (panel d), cell nitrogen (panel e) versus 


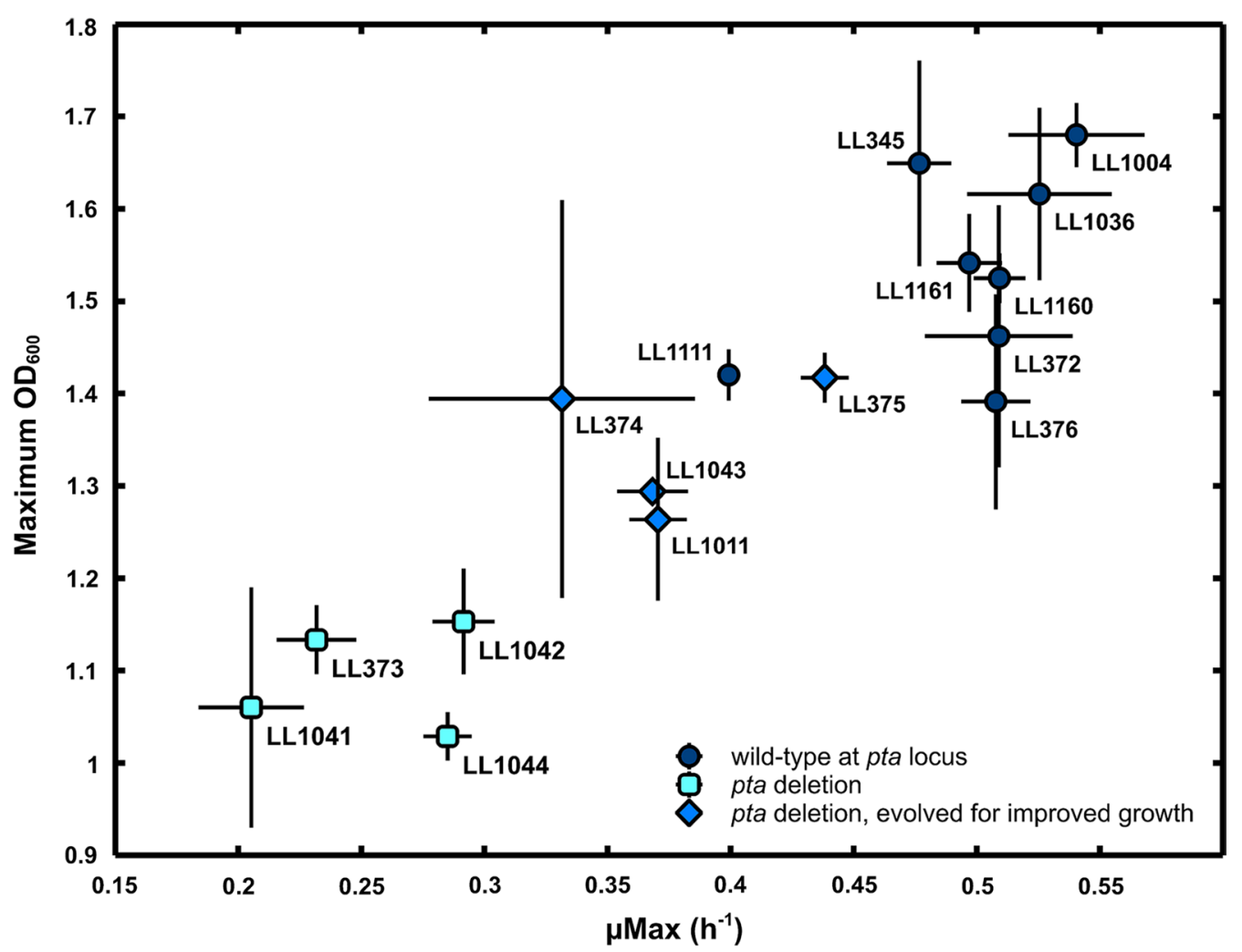

Fig. 2 The maximum growth rate versus the maximum cell density as measured by $\mathrm{OD}_{600}$ for strains described in this study. Strains were cultured in a microplate placed in a plate reader, incubated at $55^{\circ} \mathrm{C}$ on modified low-carbon medium with $5 \mathrm{~g} / \mathrm{L}$ cellobiose. Error bars represent one standard deviation, $n \geq 3$ cultures
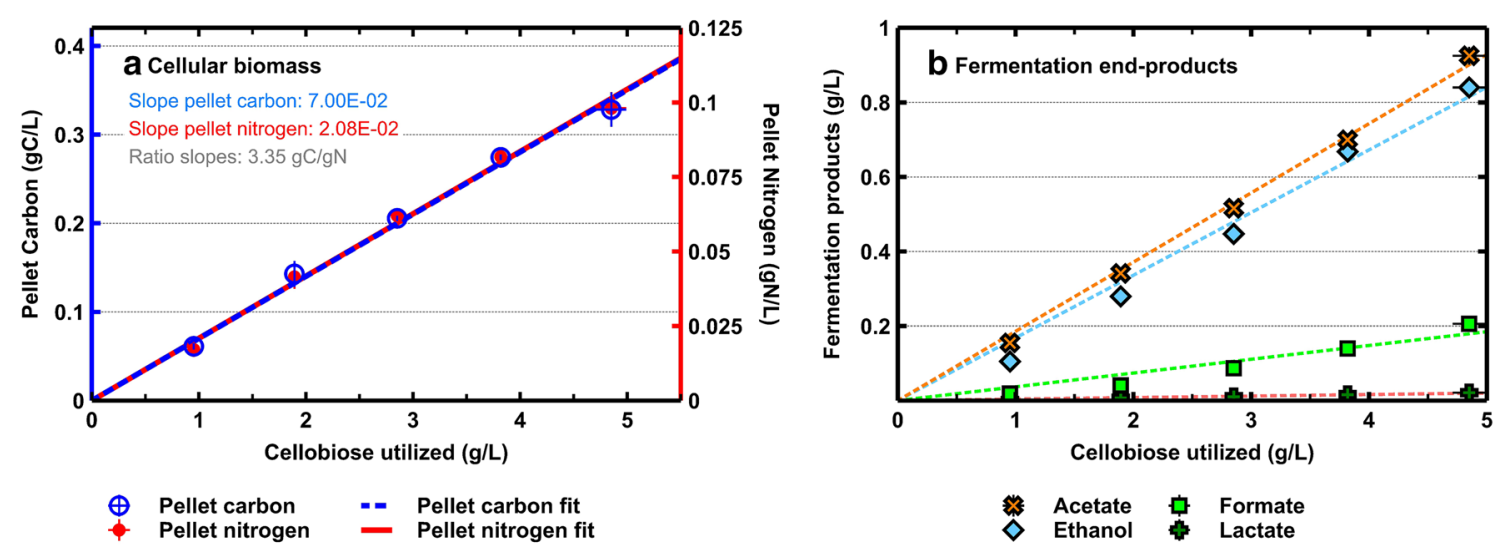

Fig. 3 Cellular biomass (a) and fermentation end-product (b) formation for five different cellobiose loadings at dilution rate of $0.1 \mathrm{~h}^{-1}$ for Clostridium thermocellum wild-type (LL1004) at steady state. Both cell yield and product formation have a linear relation with the amount of substrate utilized. Steady-state cell concentration is represented by both pellet carbon and pellet nitrogen, which both have a linear relation to cellobiose utilized. Error bars represent one standard deviation

that of ethanol. Panel $\mathrm{f}$ represents the ratio of cell carbon to cell nitrogen.

Panels a to e show that deleting either hpt and spoOA and/or $l d h$ has minimal effect on ethanol and cell biomass at steady state; strains containing only these deletions (LL345, LL1036, LL376 and LL372) shown in dark blue circles are grouped with LL1004 (wild-type). Deleting pta (light blue squares, strains LL1041, LL1042, LL373 and 

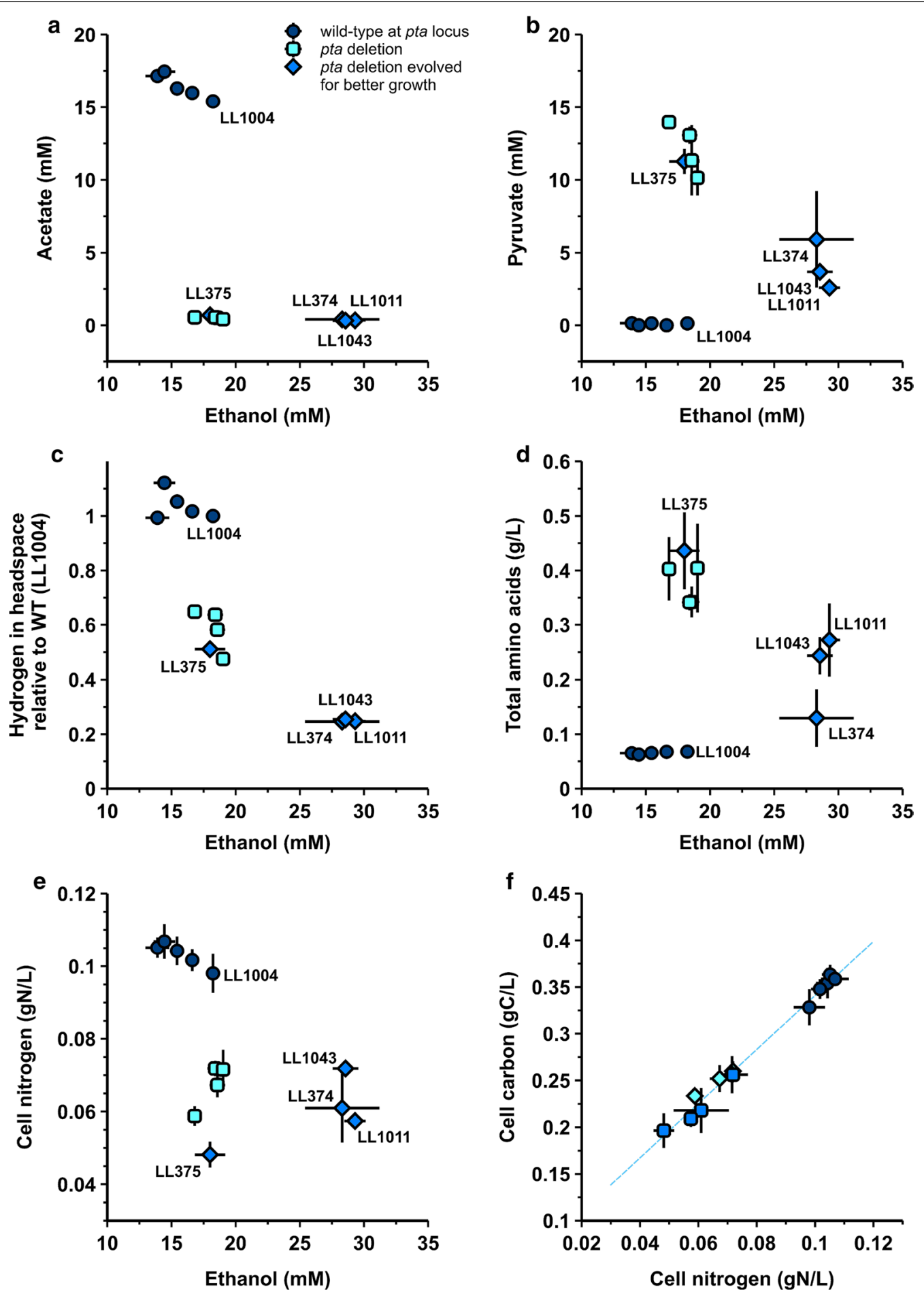

Fig. 4 A comparison of steady-state production level of ethanol vs. acetate (a), pyruvate (b), hydrogen (c), total amino acids (d) and cell nitrogen (e, a proxy for cell biomass) for strain lineages 1 and 2. f Shows data for cell carbon to cell nitrogen for the same data set for every strain. Strains with wild-type pta are represented by round shaped dark blue data points, strains with pta deleted (unmarked deletion or merodiploid) are square shaped light blue data points and strains with pta deleted but evolved for improved growth are diamond shaped blue data points. The evolved strains with pta deleted (LL374, LL375, LL1011 and LL1043) are indicated with their strain name as is wild-type (LL1004). Error bars represent one standard deviation, $n \geq 4$. This figure does not include data for strains LL1111, LL1160 and LL1161, and the data used here is not normalized for differences in cellobiose feed concentration or for measured dilution rate 
LL1044) results in decreased acetate production and a lower steady-state biomass concentration. However, this decrease is not accompanied by an increase in ethanol; there is instead an increase in pyruvate (b), and free total amino acids (d), and a decrease in hydrogen (c) and cell nitrogen (cell biomass, e). It seems that under the tested conditions the primary response of metabolism after blocking acetate production is an increase in pyruvate and amino acids (with valine, alanine, glutamine and isoleucine being highest detected). Four strains were evolved for improved growth (represented by blue diamonds) as described earlier, and this results in an increase in ethanol (panels a-e) for strains LL374, LL1011 and LL1043 accompanied by a decrease in pyruvate, hydrogen and amino acids. Strain evolution after pta deletion (panel e) does not recover the decreased cell biomass concentration. For all the strains the ratio between cell carbon and nitrogen remains constant (panel f). Steady-state hydrogen (c) decreases further with increasing ethanol concentration due to strain evolution. Out of the four evolved strains with pta deleted, LL375 is the only strain where ethanol production is not improved. Steady-state pyruvate, hydrogen, amino acids and cell nitrogen do not change after adaptation and the strain remains grouped with the unevolved pta-deleted strains (in light blue squares).

\section{Control of lactate flux}

Lactate production in C. thermocellum is controlled by the lactate dehydrogenase gene $(l d h)$, which is constitutively expressed at high levels, but is allosterically controlled by fructose 1,6-bisphosphate (FBP) [11]. Under normal conditions, $C$. thermocellum ferments $\mathrm{C}_{6}$ sugars to mainly acetate and ethanol. When the pathways for these fermentation end-products are blocked, intracellular metabolites accumulate, including FBP, which activates the Ldh enzyme. During fermentation on cellulose, lactate usually appears only after ethanol and acetate formation is well underway [12-15], consistent with a lag in accumulation of FBP in central metabolism. Strains LL1111, LL1160 and LL1161 have the $\mathrm{Ldh}^{\mathrm{S} 161 \mathrm{R}}$ mutation which de-represses lactate production (i.e., lactate is produced all of the time, even when FBP levels are low), and explains the increased lactate production in these strains [11]. Lactate production from glucose is balanced for electrons. Under the chosen chemostat cultivation conditions, strains with a wild-type $l d h$ locus do not produce much lactate, which masked the effect of the ldh deletion.

\section{Control of acetate flux}

The most significant fermentation phenotype is the change in acetate production upon deletion of the pta gene (Figs. 4 and 5). Strains that are wild type at the pta locus produce about $17 \mathrm{mM}$ acetate. When pta is deleted, acetate production is largely eliminated (traces of acetate may be produced as a side product of other biological reactions). Deleting pta has a negative effect on ATP yield per sugar utilized in anaerobic metabolism. This loss in ATP can affect energetically intense cellular processes like protein and cell synthesis, which in case of $C$. thermocellum and its cellulosome could influence its cellulolytic capabilities. The steady-state cell concentration as shown by pellet carbon or pellet nitrogen values in Figs. 4 and 5 decreases when pta is deleted, and is not recovered after ALE. The decrease in acetate flux corresponds to an increase in pyruvate secretion. During adaptive evolution, pyruvate flux decreases, and ethanol flux increases. Of the four adapted strains (LL374, LL375, LL1011 and LL1043), three of them fit this pattern. The fourth strain (LL375) does not. In this strain adaptive evolution increased the growth rate without affecting the fermentation phenotype.

Compared to lactate, the control of acetate production is more complicated, because the pathway for conversion of glucose to acetate is not balanced for electrons (glucose $\rightarrow 2$ acetate $\left.+2 \quad \mathrm{CO}_{2}+2 \mathrm{NADH}+2 \quad \mathrm{Fd}_{\text {red }}\right)$. Thus, acetate production has to be accompanied by the production of a reduced product such as ethanol, formate and hydrogen. Under conditions of low hydrogen partial pressure (such as co-culturing $C$. thermocellum with a $\mathrm{H}_{2}$-consuming methanogen), the acetate:ethanol ratio can be as high as 8.5:1 [16]. Conversely, increasing the $\mathrm{H}_{2}$ partial pressure decreases acetate:ethanol ratio [14, 1720]. Acetate production can also be decreased by eliminating hydrogen production [21].

\section{Hierarchical clustering of carbon fluxes}

Performing hierarchical clustering on the carbon fluxes (mmol carbon/h, derived from chemostat fermentation data) for all strains (including lineage 3 ) and the important metabolites (carbon flux $>3 \%$ of total) reveals the same three clusters from Figs. 2 and 4, and gives us additional information about related metabolites. Strains in cluster 1 produce ethanol and acetate in a roughly 1:1 molar ratio. All of the strains in this cluster are wild-type for $p t a$. Strains in cluster 2 produce mostly ethanol and pyruvate. Amino acid production is elevated, particularly valine. Acetate production has been eliminated. Pellet carbon is reduced by about $50 \%$ compared with cluster 1. All of the strains in this cluster have a pta deletion. Strains in cluster 3 produce primarily ethanol (about $50 \%$ of the maximum theoretical yield). Pyruvate and amino acid production is lower than cluster 2 (pta deletion), but higher than cluster 1 (wild type). This cluster includes 3 of the 4 adapted strains, as well as strain LL1161. 


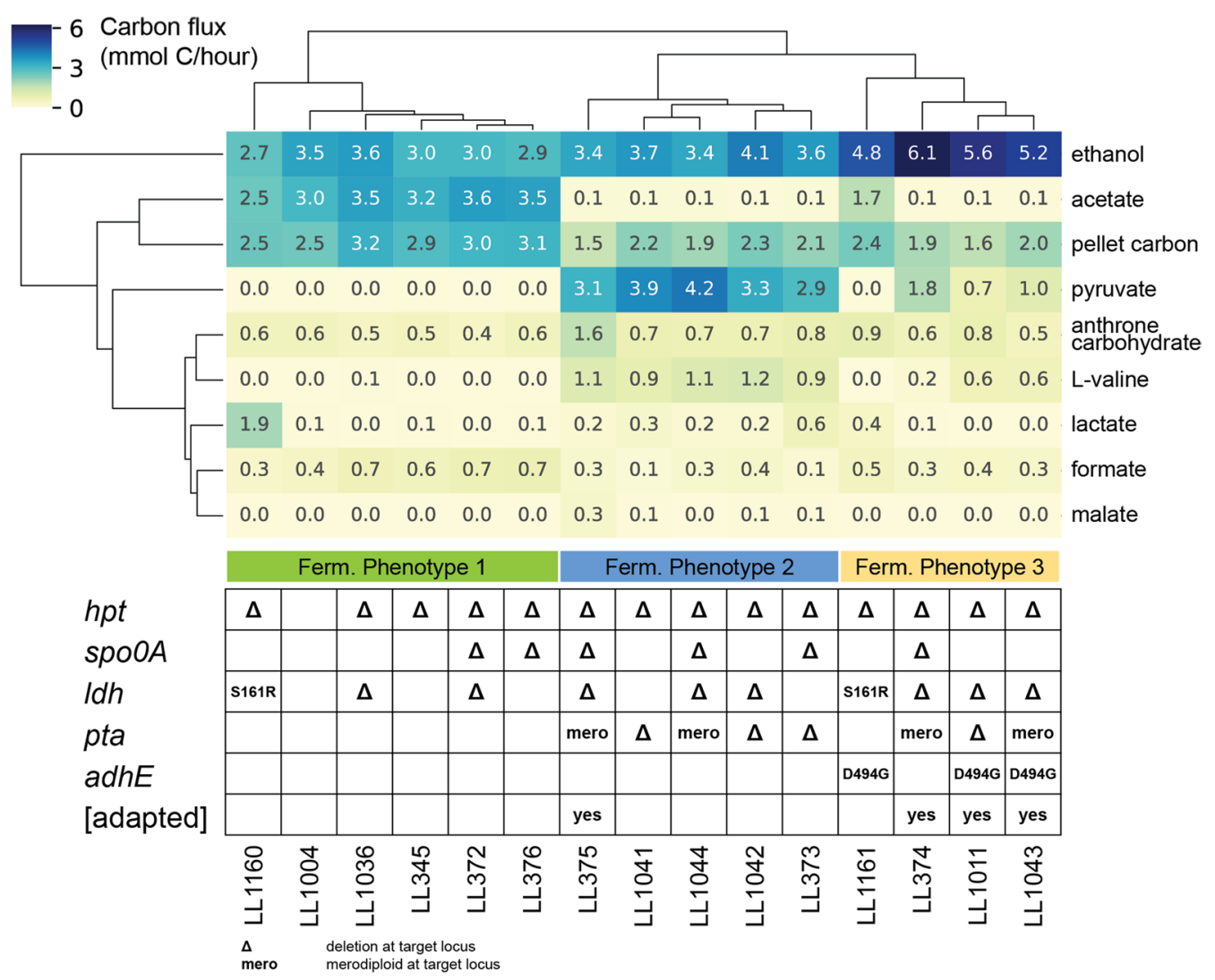

Fig. 5 Clustered fermentation data. Units are carbon flux (mmol C-atoms/h). Only products accounting for $>3 \%$ of the total carbon flux were included. Hierarchical clustering was performed for both strains and products using an averaged linkage method and Euclidean distance metric. The full set of fermentation data is available in Additional file 1: Table S1

\section{Sequencing data}

Mutations in each strain were identified by wholegenome sequencing (see "Methods" for details). A full list of all mutations is available in Additional file 2: Table S2.

\section{RNAseq mutations}

RNAseq data contain information about mutations, in addition to gene expression, and these mutations were added to the mutations found by whole-genome sequencing. For most strains, the whole-genome sequencing data and RNAseq data showed similar results. For strain LL374, several additional mutations were found using RNAseq that were not observed based on whole-genome resequencing. Re-analysis of the sequencing data showed that many of these missing mutations were present in the sequencing data at a low frequency $(\sim 20 \%$ of reads for a given mutation, which was below the cutoff used for the initial analysis). Since these mutations were present at near $100 \%$ frequency in the RNAseq data, this suggests that these mutations belong to a subpopulation that overtook the culture at some point after the whole-genome resequencing.

\section{Merodiploid pta locus}

All of the pta deletion strains were created in a manner to allow the removal of selectable markers, resulting in an unmarked deletion. After adaptation, however, three of the four adapted strains (LL374, LL375 and LL1043, but not LL1011) were found to be merodiploid at the pta locus (i.e., they have a truncated copy of the pta gene, Additional file 3: Figure S3). The merodiploid stage is part of the gene deletion process where two copies of the downstream homology flanking region are present [22]. Inspection of reads that did not map to the $C$. thermocellum chromosome revealed a number of reads that mapped to the $\mathrm{P}_{\mathrm{gapDH}}{ }^{-c a t-h p t}$ cassette from plasmid pMU1817 (accession number MK036504) used to delete the pta gene [8]. Re-mapping all of the reads to an in silico reconstruction of the merodiploid locus provides evidence that this configuration is present (sequence data from accession numbers in Table 2). First, there are no reads mapped to the $5^{\prime}$ end of the pta gene (this also shows that this gene has been functionally inactivated). Second, the $5^{\prime}$ flanking region and gapDH promoter region have twice the read depth of the other 
Table 1 Mutations associated with changes in gene expression

\begin{tabular}{|c|c|c|c|c|c|}
\hline Annotation name & Locus description & Parent & Strain & Fold-change & $p$-value \\
\hline 89 bp upstream of Clo1313_0099 & Thiamine pyrophosphate TPP-binding domain-containing protein & LL1036 & LL1042 & 4.33 & 0.0017 \\
\hline 10 bp upstream of Clo1313_0779 & Copper amine oxidase-like domain-containing protein & LL1044 & LL374 & 0.47 & 0.0003 \\
\hline 81 bp upstream of Clo1313_1055 & Major facilitator superfamily MFS_1 & LL1044 & LL375 & 2.29 & 0.0020 \\
\hline 8 bp upstream of Clo1313_1397 & Copper amine oxidase-like domain-containing protein & LL1044 & LL374 & 0.47 & 0.0010 \\
\hline 14 bp upstream of Clo1313_1989 & VTC domain & LL345 & LL376 & 0.52 & 0.0001 \\
\hline 197 bp upstream of Clo1313_2323 & $A B C$ transporter related & LL1044 & LL374 & 2.52 & 0.0005 \\
\hline
\end{tabular}

regions, suggesting that they are present in two copies each, which is what would be expected for a merodiploid strain (the gapDH promoter region is present once at the gapDH locus on the chromosome and once in the $\mathrm{P}_{\text {gapDH}}$-cat-hpt cassette). Third, there is direct evidence of the $\mathrm{P}_{\text {gapDH}}$-cat-hpt cassette integration at the $p t a$ locus based on paired read data where one read pair maps unambiguously to the cassette and one maps unambiguously to the pta locus. Fourth, the size of the pta and gapDH loci was analyzed by PCR (Additional files 3 and 4: Figures S3 and S4). The PCR data support the conclusions from the Illumina sequencing data, namely that strains LL1043 and LL1044 are merodiploid at the pta locus.

In the case of strain lineage 1 the pta locus shows an unmarked deletion in strain LL1042. Strain LL1011, which is derived from LL1042, also shows an unmarked deletion. Strain LL1043, however, shows a reversion to the merodiploid genotype. Presumably the merodiploid genotype existed as a small population in strain LL1042 (the sequencing data for strain LL1042 do not show any evidence of this, which suggests this population was $<1 \%$ of the total, and this was confirmed by PCR). Furthermore, there must have been a selective advantage for this population to outcompete the unmarked deletion population during the selection for faster growth in the $\mathrm{pH}$ auxostat. The merodiploid strain has two changes that might explain this. One change is the presence of the hpt gene, which would complement the $h p t$ deletion that was introduced to allow 8AZH counter-selection [8]. Another change is increased expression of the acetate kinase (ack) gene, presumably via read-through from the $\mathrm{P}_{\text {gapDH }}$ promoter. The maximum growth rate data only show very minimal advantage for strain LL1043 vs. LL1011 (Fig. 2), so the growth advantage must be specific to conditions used to generate the adapted strains.

In the case of strain lineage 2, the pta locus of strain LL1044 is merodiploid, and this genotype was passed on to both LL374 and LL375. This appears to be an intentional choice in strain construction. Van der Veen et al. note that the unmarked $\Delta l d h \Delta p t a$ strain had a growth defect, and thus the merodiploid strain was chosen for chemostat evolution [9].

\section{Convergent evolution mutations}

Mutations overrepresented in strains with phenotype 3 (high ethanol) are most likely to actually contribute to that phenotype. There are three genes in this category: Clo1313_0670, adhE and Clo1313_2130. Gene Clo1313_0670 is annotated as a zinc/iron permease. In strain LL374, the mutation is $28 \mathrm{bp}$ upstream of the Clo1313_0670 gene, which results in a 63\% decrease in expression $(p=0.006)$. In strain LL1011, the mutation is a frameshift. Both of these mutations decrease the activity of this gene. This may be related to ethanol tolerance. A strain of $C$. thermocellum adapted for improved ethanol tolerance acquired a T186M mutation in this gene (ATCC 27405 Cthe_3117 locus) [23].

In the $a d h E$ gene, strains LL1011 and LL1043 both had the same D494G mutation. Furthermore, this is the only mutation that both strains share, suggesting that this mutation may be responsible for the increase in ethanol production observed in those strains. Furthermore, mutations in $a d h E$ have been observed in other strains of C. thermocellum adapted for increased ethanol tolerance (including the D494G mutation) [23, 24].

Very little is known about Clo1313_2310. In strain LL1043, the gene was mutated by insertion of an IS120 transposon, which likely inactivated the gene.

\section{Increased ethanol production in strain LL374}

Of the three adapted $\Delta l d h \Delta p t a$ strains that showed increased ethanol yield (LL374, LL1011 and LL1043), two can be explained by the $a d h E^{\mathrm{D} 494 \mathrm{G}}$ mutation. Since strain LL374 does not have this mutation, we need to consider other explanations. Most strains have fewer than 20 mutations, however strain LL374 has 103 (Additional files 2 and 5: Table S2 and Figure S5). One possible explanation for the increased mutation rate is a mutation in DNA polymerase III (Clo1313_1219). The homolog of Clo1313_1219 in E. coli is dnaE. Mutations in dnaE have been shown to generate mutator phenotypes in $E$. coli $[25,26]$. 
A possible explanation for the increase in ethanol production is the disruption of $h f_{s} B$ (hydrogenase-Fe-S, Clo1313_1795). Strain LL374 has two point mutations in this gene, one of which is a frame-shift mutation which would be expected to eliminate activity. Disruption of $h f s B$ in $C$. thermocellum has previously been shown to increase ethanol production by $52 \%$ (from $37 \%$ of theoretical to $55 \%$ of theoretical) [27]. This increase is similar to what was observed for strain LL374 and thus is a plausible explanation for the increase in ethanol production.

Other mutations are described and evaluated in Additional file 6: Supplemental text S6.

\section{Re-introduction of the AdhE ${ }^{\mathrm{D} 494 \mathrm{G}}$ mutation}

The bifunctional alcohol and aldehyde dehydrogenase AdhE performs the conversion of acetyl-CoA into ethanol by two reductive steps and is essential for ethanol production in C. thermocellum [11]. In C. thermocellum, AdhE uses NADH as a cofactor for both reductive steps (acetyl-CoA reduction (ALDH) and subsequent acetaldehyde reduction (ADH)). A mutation that causes an aspartate-to-glutamate mutation at position 494 (D494G) has been shown to allow the ADH reaction to use either $\mathrm{NADH}$ or NADPH [28]. Mutations in the $a d h E$ gene have been associated with increased ethanol production in $C$. thermocellum [29] as well as other thermophilic bacteria such as Thermoanaerobacterium saccharolyticum [30].

In order to identify causal links between a single mutation and phenotype, it is important to reintroduce the mutation in a "clean" strain background, without other secondary mutations that could confound interpretation of the results. Our ability to re-introduce point mutations in C. thermocellum is limited by the available genetic tools, and we were thus only able to test a single point mutation. We chose to test the D494G mutation in AdhE, since we know that the $a d h E$ gene is essential for ethanol production [11], and the mutation was the only mutation shared by both of the adapted strains in lineage 1 (strains LL1011 and LL1043, Fig. 6). To test this hypothesis, we re-introduced this mutation into a strain that was wild type for $l d h$ and pta (strain LL345). Current genetic tools for $C$. thermocellum do not allow us to directly reintroduce the point mutation. Instead, we had to delete the adhE gene (resulting in strain LL1111) and then insert an $a d h E$ gene with either the wild-type sequence (resulting in strain LL1160) or the D494G mutation (strain LL1161). Since strains LL1160 and LL345 are wild type at the $a d h E$ locus, comparing their fermentation phenotypes allows us to see the effect of other mutations that occurred during the construction of LL1160. Strain LL1160 had a fermentation profile similar to that of LL345 (i.e., both are found in cluster 1 of the fermentation data, Fig. 5), although lactate production had increased due to a mutation that eliminated fructose 1,6-bisphosphate regulation of the $l d h$ gene [11]. Comparing strains LL1160 and LL1161 shows the effect of the D494G mutation, which is to increase ethanol production at the expense of lactate and acetate production (i.e., move from fermentation cluster 1 to cluster 3 ). This single point mutation can explain about $90 \%$ of the increase in ethanol production observed in strains LL1011 and LL1043.

\section{Gene expression during chemostat growth}

Gene expression in each strain was determined by RNAseq (Additional files 7, 8 and 9: Table S7, Table S8 and Table S9). Comparing each evolved strain to a strain that is wild type at the $l d h$ and pta loci (LL345) showed only a small number of significant differences (Additional file 10: Figure S10).

\section{Mutations correlated to changes in gene expression}

To identify mutations that were responsible for changes in gene expression, we looked at mutations that occurred upstream of a given gene, and then compared gene expression in that strain with expression in the parent strain. Of the 22 origin mutations that were found to be upstream of a gene, 6 were significant at the $p=0.05$ level (corrected for 22 multiple tests by the Bonferroni method) (Table 1). Of these mutations, the only one with a distinct fermentation phenotype is the mutation in strain LL1042 upstream of Clo1313_0099, which is the valine biosynthesis operon. It is possible that this mutation explains the increase in valine production in this strain, however there are several other strains with elevated valine production that do not have this mutation.

\section{Batch cultivation on high cellulose loadings}

Under industrially relevant cellulose loadings $(\geq 100 \mathrm{~g} / \mathrm{L}$ cellulose) wild-type $C$. thermocellum demonstrates three significant features. It can solubilize and ferment 80-100 g/L crystalline cellulose [14, 31]. Cell growth stops at around $50 \%$ solubilization while the culture continues to solubilize and metabolize the remaining cellulose without apparent effects on rate or extent of solubilization [13]. Lastly, near the point of maximum cell concentration the culture switches to uncoupled metabolism and produces higher alcohols $\left(>\mathrm{C}_{2}\right.$, notably isobutanol and 2,3-butanediol) as well as continues to produce significant amounts of amino acids (notably valine and alanine) [13]. All of these events only become evident when culturing under high cellulose loading conditions, and have been attributed to overflow metabolism around the pyruvate node [13].

Wild-type C. thermocellum has been shown to be capable of solubilizing between 77.5 and 96.7 g glucose equivalents/liter, at a rate of $2.09-2.88 \mathrm{~g}$ gluc eq/L/h 


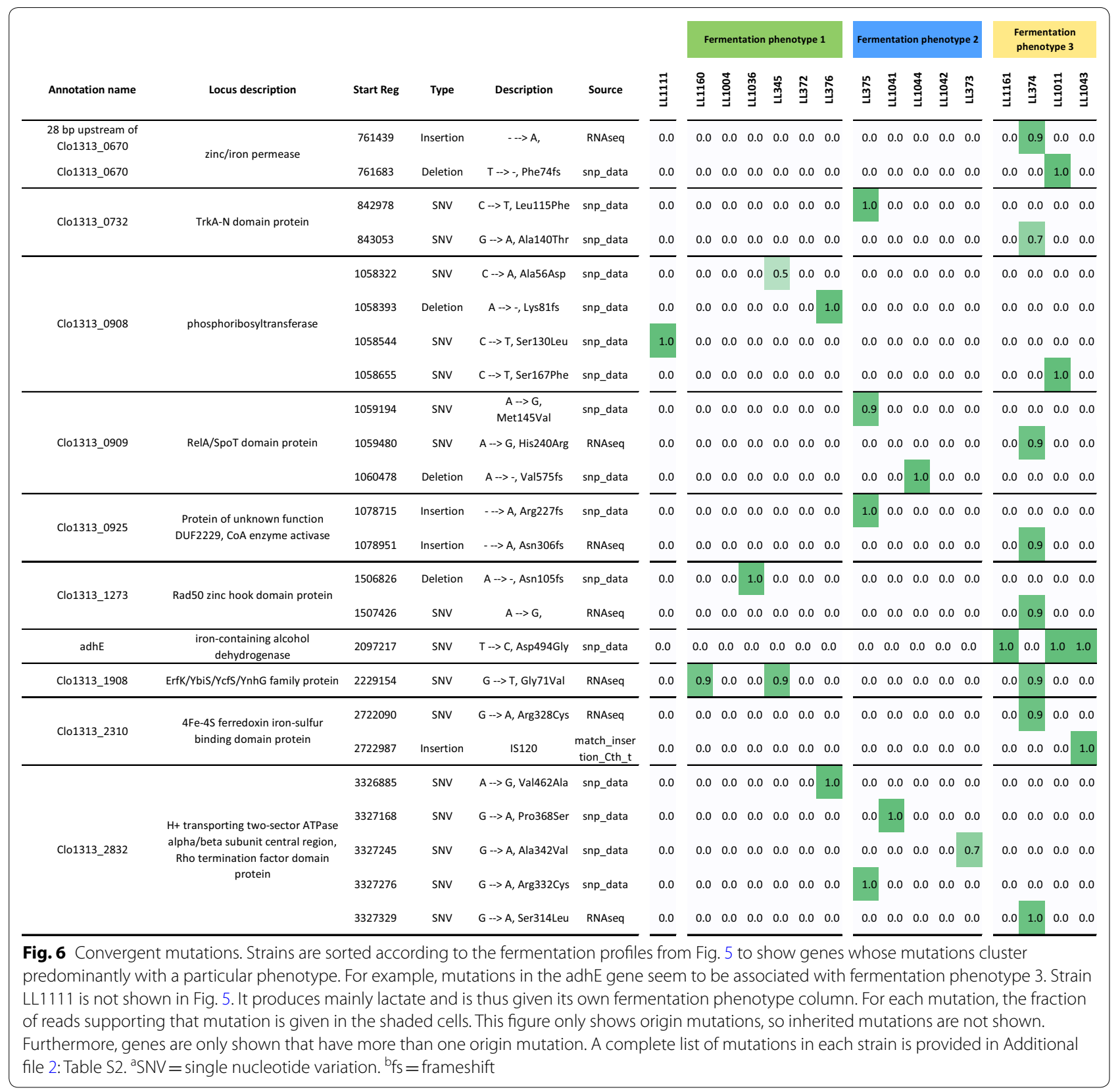

when cultivated on up to 103.4 g gluc eq/L [13]. Figure 7, in the left panel of figures, shows the extent of solubilization, the rate of solubilization and pellet nitrogen (a proxy for cell concentration) for the four end-strains of the strain lineages 1 and 2. Each of the four strains was able to emulate the extent of solubilization for wild-type when cultivated on loadings of $120 \mathrm{~g}$ gluc eq/L, the highest amount of cellulose was solubilized by strain LL374 at $109.2 \mathrm{~g}$ gluc eq/L. Since the ATP yield per sugar is limited in anaerobes, and production of cellulosomes is energetically expensive, reducing ATP supply by deleting pta could result in decreased cellulosome production, which would have a negative effect on the rate of cellulose solubilization. Two of the strains tested (LL374 and LL1043) had lower maximum solubilization rates, but remained close to the wild-type solubilization rate. The rate value for strain LL375 was within the range of wild-type, while strain LL1011 surpassed the maximum rate of solubilization at $3.19 \mathrm{~g}$ gluc eq/L/h compared to wild-type $C$. thermocellum.

The maximum cell concentration $[\text { cell }]_{\max }$ for wildtype $C$. thermocellum grown on $103.4 \mathrm{~g}$ gluc eq/L is 


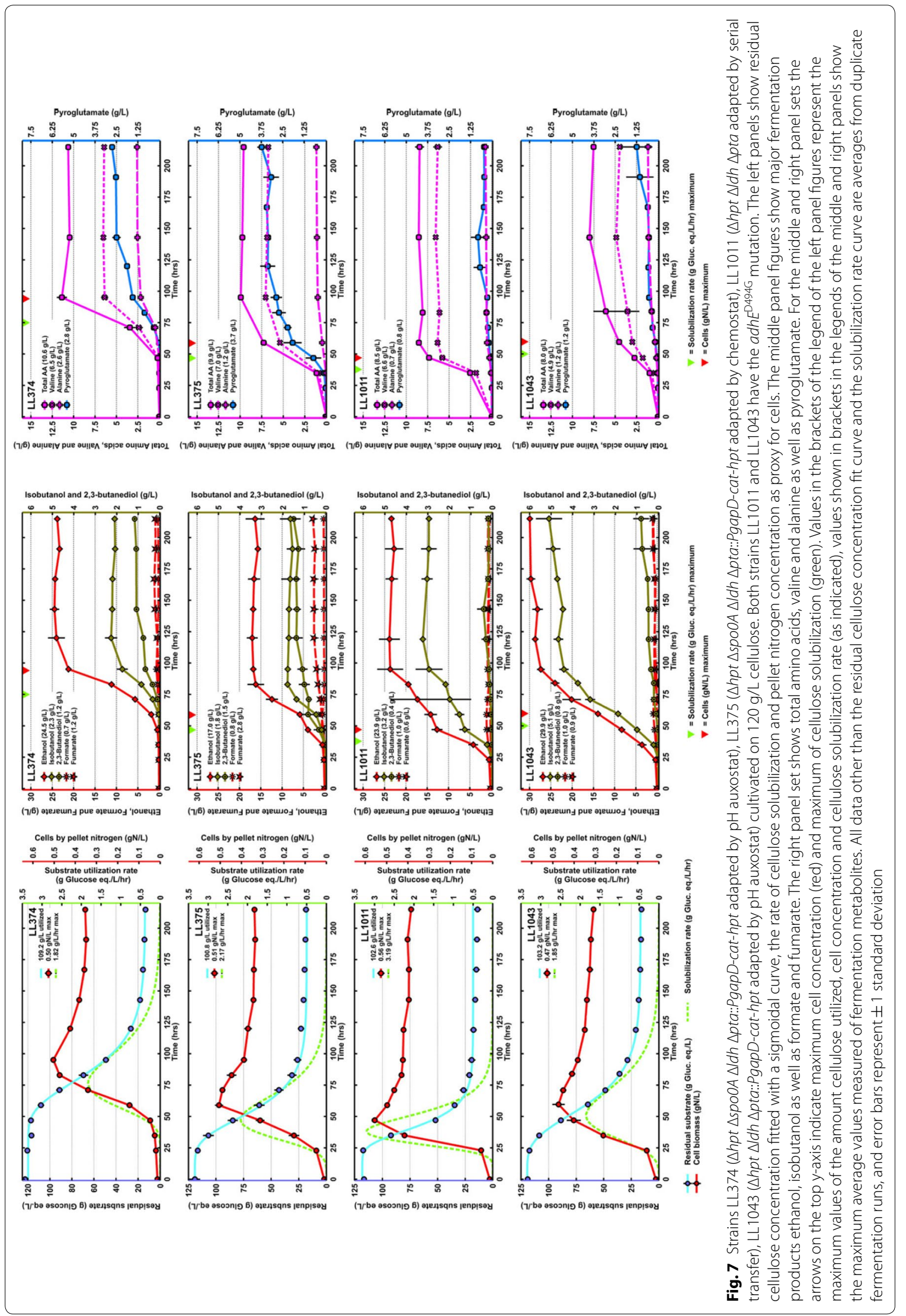


documented at $0.64 \mathrm{~g} \mathrm{~N} / \mathrm{L}$ [13]. None of the four strains tested here exceeded that value, $(0.47-0.56 \mathrm{gN} / \mathrm{L})$. One possible reason for this lower cell concentration is the deletion of $p t a$, which results in a loss of ATP. In the chemostat experiments strains with pta knocked out had a lower steady-state cell concentration. However, it is important to note that the lower amount of cells (biocatalyst) did not diminish or negatively affect the extent of solubilization. Just as with wild-type, for all strains the maximum rate of cellulose solubilization happens before peak cell growth (shown in the left panel set of figures and indicated by the green (solubilization rate) and red (cells) arrows in the middle and right panels of Fig. 7). More extensive metabolic engineering than described here by knocking out genes involved in acetate, lactate, formate and hydrogen production affected the growth rate of the newly generated strain, and was only partially recovered after extensive evolutionary engineering involving serial transfers and selection \& screening based ALE approach $[32,33]$. To avoid negative effects on cell physiology and growth performance current metabolic engineering strategies involve introducing heterologous genes for ethanol-producing pathway [11, 29, 33, 34]; Hon et al. [15], describe expressing four genes from Thermoanaerobacterium saccharolyticum in C. thermocellum that increased ethanol titer and yield while not negatively affecting growth rate or the ability to solubilize cellulose.

Under similar high solids cultivation conditions as described here, wild-type $C$. thermocellum makes $13.9 \mathrm{~g} / \mathrm{L}$ ethanol, $11.3 \mathrm{~g} / \mathrm{L}$ acetate, $2.6 \mathrm{~g} / \mathrm{L}$ formate, $0.8 \mathrm{~g} / \mathrm{L}$ fumarate and $0.8 \mathrm{~g} / \mathrm{L}$ lactate [13]. While both the acetate and lactate pathways are disrupted for all strains in the high cellulose fermentation experiments, there were nonnegligible amounts of acetate $(1.2-3.1 \mathrm{~g} / \mathrm{L})$ and lactate (1.3-1.8 g/L) detected (see Additional file 11: Table S11). As mentioned earlier, this is likely a result of side product formation from other biological reactions. Formate reaches concentrations between 0.7 and $1.0 \mathrm{~g} / \mathrm{L}$, which is an actual decrease compared to wild-type. There is a notable increase in extracellular fumarate for the end-strains from lineage 2; LL374 (1.2 g/L) and LL375 $(2.8 \mathrm{~g} / \mathrm{L})$ while strains from lineage 1 are similar to wildtype (0.6 g/L for LL1011 and 0.9 g/L for LL1043).

Higher alcohols as well as extracellular amino acids are undesired fermentation products in a for-ethanol engineering scenario. Wild-type $C$. thermocellum produces $1.6 \mathrm{~g} / \mathrm{L}$ isobutanol, $0.42 \mathrm{~g} / \mathrm{L}$ 2,3-butanediol, and total amino acids were determined at $7.5 \mathrm{~g} / \mathrm{L}$ (with valine at $4.5 \mathrm{~g} / \mathrm{L}$ and alanine at $1.5 \mathrm{~g} / \mathrm{L}$ ) and pyroglutamate at $0.2 \mathrm{~g} / \mathrm{L}$. The pyroglutamate detected here is believed to be the result of a degradation reaction of glutamate and of glutamine at increased temperatures based on [35, 36]. Both isobutanol and free amino acids (including pyroglutamate) remain a major side product in engineering-for-ethanol followed by ALE (Fig. 7 the middle and right panels); with $l d h$ and pta knocked out, valine becomes the second most abundant fermentation product with a maximum concentration of $7.0 \mathrm{~g} / \mathrm{L}$ for stain LL375 and a minimum concentration of $4.9 \mathrm{~g} / \mathrm{L}$ for strain LL1043. To reduce the superfluous production and excretion of amino acids, one option is to knock out parts of nitrogen metabolism. Rydzak et al. have approached this by deleting a type I glutamate synthetase $g \ln A$ which resulted in lower amino acid production and a higher ethanol yield [37]. For the chemostat experiments the free amino acids concentration and extracellular pyruvate went down after ALE. Under high cellulose conditions pyruvate is present for all four strains $(0.9-1.3 \mathrm{~g} / \mathrm{L}$ see Additional file 11: Table S11), the maximum concentration pyruvate documented for wild-type C. thermocellum is $0.3 \mathrm{~g} / \mathrm{L}$.

Strains LL1011 and LL1043 from lineage 1 produced more isobutanol than strains LL374 and LL375 from lineage 2, which produced more than wild-type. However, the two strains from lineage 2 produced more 2,3-butanediol than the strains from lineage 1 , which produced more than wild-type. It remains unclear if this is due to the presence or absence of the $A d h E^{\mathrm{D} 494 \mathrm{G}}$ mutation. While we do not know of reported attempts of engineering $C$. thermocellum for butanediols, efforts have been made to engineer $C$. thermocellum into producing only isobutanol with plasmid-based heterologous gene expression using genes from Geobacillus stearothermophilus and Lactococcus lactis [38]. C. thermocellum's native ability to produce isobutanol, which is believed to involve both ketoisovalerate ferredoxin-dependent reductase (KOR) activity and pyruvate ferredoxin oxidoreductase (PFOR) activity [38, 39], has not been subject to engineering. However, Hon et al. describe one of the side effects of knocking out a specific pfor gene which eliminated native isobutanol production, this would have the potential to redirect metabolism towards ethanol. The maximum isobutanol titer detected in this set of experiments was $5.1 \mathrm{~g} / \mathrm{L}$ by strain LL1043, which is close to the maximum titer reported for a for-isobutanol-engineered strain reaching a value of $5.4 \mathrm{~g} / \mathrm{L}$ at a yield of $48 \%$ [38]. Note that the results for the isobutanol engineered strain were obtained under different cultivation conditions.

Finally, the ethanol titer was significantly higher for three out of the four strains compared to wild-type. LL1043 had the highest ethanol titer reported to date at $29.9 \mathrm{~g} / \mathrm{L}$. Although it seems that the $A d h E^{\mathrm{D} 494 \mathrm{G}}$ mutation caused the ethanol titer for both strains in lineage 1 to be higher, as with the results from the chemostat experiments, LL374 also has a very high ethanol titer at $24.5 \mathrm{~g} / \mathrm{L}$. For high cellulose loadings LL374 actually 
has a higher ethanol titer compared to LL1011 (with the $a d h E^{\mathrm{D} 494 \mathrm{G}}$ mutation). LL1043 has both the highest ethanol titer and isobutanol titer, the lowest free amino acids concentration and the lowest [cell $]_{\max }$ from all four strains, while it went through the second highest amount of solubilized cellulose. In the chemostat experiments the absolute difference in ethanol titer between strains LL374, LL1011 and LL1043 was minimal, but there was no nominal improvement for strain LL375 after ALE. Under high cellulose concentration strain LL375 still produces high concentrations of amino acids and pyruvate (see Additional file 11: Table S11) and only a small improvement in ethanol titer compared to wild-type. Notwithstanding the extensive analysis described in this paper, we did not gain additional insight into why ALE improved the growth rate but not the ethanol titer for this strain. Carbon recoveries for the cellulose fermentations are listed in Additional file 11: Table S11, the highest recovery was for strain LL1043 at 94.2\%, with strains LL374 (78.5\%) and LL1011 (77.9\%) around similar values as described for wild-type (80.8\%) [13] and only slightly lower for strain LL375 (71.5\%).

Metabolic engineering has been applied to cellulolytic microorganisms as genetic tools have become available, and in a few cases has involved ALE. Guedon et al. [40] heterologously expressed pyruvate decarboxylase and alcohol dehydrogenase II from Zymomonas mobilis in the mesophile Clostridium cellulolyticum increasing biomass concentration and cellulose consumption as well as a $50 \%$ increase in ethanol titer. In $2012 \mathrm{Li}$ et al. inactivated lactate and malate dehydrogenase in C. cellulolyticum resulting in a titer of $2.7 \mathrm{~g} / \mathrm{L}$ ethanol from cellulose [41]. Tolonen et al. increased the ethanol tolerance of Clostridium phytofermentans by serial transfer and followed an approach similar to Guedon et al., leading to an ethanol titer of around $0.9 \mathrm{~g} / \mathrm{L}$ [42]. Chung et al. engineered the hyperthermophile Caldicellulosiruptor bescii to produce $0.6 \mathrm{~g} / \mathrm{L}$ ethanol from switchgrass by heterologously expressing adhE from C. thermocellum [43]. Metabolic engineering studies related to cellulolytic organisms other than C. thermocellum have often targeted higher alcohols. These include production of isobutanol in the mesophilic C. cellulolyticum via heterologous expression of genes from other mesophiles [44-46]. Clostridium cellulovorans, also a mesophile, has been engineered to produce n-butanol via a combination of heterologous expression of genes from Clostridium acetobutylicum and ALE [47-50].

It is instructive to consider microorganisms to which metabolic engineering, ALE, and genomics-enabled approaches have been applied more extensively than is the case for $C$. thermocellum and other cellulolytic anaerobes. Corynebacterium glutamicum is case in point [51].
Becker et al. combined metabolic modeling, ${ }^{13} \mathrm{C}$ flux analysis and metabolic engineering to create a lysineoverproducing C. glutamicum strain with lysine production up to $120 \mathrm{~g} / \mathrm{L}$ [52], competitive with classically derived strains. Mahr et al. used a combination of iterative cultivation and fluorescence-based cell sorting to increase both growth rate and product formation while reducing by-product formation [53]. Lee et al. used a combination of metabolic engineering and adaptive evolution to enable a C. glutamicum strain to utilize cellobiose and xylose [54]. Radek et al. applied a combination of automated ALE in microplates based on serial transfer of a xylose utilizing strain of $C$. glutamicum increasing its growth rate 2.6-fold [55]. Zhang et al. engineered C. glutamicum by gene inactivation, gene knock-out and overexpression towards a L-ornithine titer of $18.7 \mathrm{~g} / \mathrm{L}$ [56]. Wen and Bao [57] used pathway engineering targeting metabolic control to produce $62.5 \mathrm{~g} / \mathrm{L}$ lysine from corn stover hydrolysate. C. glutamicum has been developed to the point that it may plausibly be considered as an alternative to $E$. coli as a platform for products other than amino acids $[58,59]$.

Looking toward the future, improved production of ethanol, and eventually other products, by $C$. thermocellum is reasonable to anticipate in light of what has been accomplished with more extensively studied microorganisms. Although ethanol production exceeding $30 \mathrm{~g} / \mathrm{L}$ has yet to be reported for C. thermocellum, the organism can grow on both cellulose and cellobiose in the presence of $50 \mathrm{~g} / \mathrm{L}$ ethanol following ALE via serial transfer [24]. Experience with other microorganisms suggests that the difference between maximum product concentrations tolerated and produced can be closed with sufficient effort [60], with propanediol in E. coli being a prominent example. The example of the hemicellulose-fermenting T. saccharolyticum, which has been engineered to produce $>60 \mathrm{~g} / \mathrm{L}$ ethanol [61], further supports the potential for developing $C$. thermocellum into an industrial microorganism.

\section{Conclusions}

In contrast to knocking out $l d h$, which has minimal influence on fermentation end-products, deleting pta causes a shift from acetate production to pyruvate and amino acids and a decrease in biomass (including growth rate) while not increasing ethanol production. After ALE (adaptive laboratory evolution), metabolism for three out of four strains with $l d h$ and pta knocked-out shifts from extracellular pyruvate and free amino acids to ethanol.

The distribution of fermentation products is generally not regulated at the transcript level (with one minor exception for valine in strain LL1042). 
The $a d h E^{\mathrm{D} 494 \mathrm{G}}$ mutation is important for ethanol production. Re-introducing this mutation into a strain with a wild-type pta locus resulted in an ethanol yield of $45 \%$ of the theoretical maximum, compared to $\sim 50 \%$ for the evolved $l d h$ pta deletion strains on $5 \mathrm{~g} / \mathrm{L}$ cellobiose. At higher substrate loadings, we observed higher levels of ethanol production in strain LL1043 compared to strain LL1011. Since both strains contain the $a d h E^{\mathrm{D} 494 \mathrm{G}}$ mutation, the phenotype must result from one of the other mutations. Strain LL374 showed increased ethanol production, but does not have the $a d h E^{\mathrm{D} 494 \mathrm{G}}$ mutation (or any other mutations in $a d h E)$. In that strain, the most likely candidate is a frameshift mutation in the $h f_{s} B$ hydrogenase gene, however confirmation of this hypothesis awaits further experimental data.

The flux split between ethanol and acetate is likely controlled by availability of electrons, not carbon. Evidence supporting this hypothesis is that pyruvate accumulates initially upon deletion of pta (and presumably acetyl-CoA accumulates as well), but ethanol production is unchanged. By contrast, introducing the $a d h E^{\mathrm{D} 494 \mathrm{G}}$ mutation immediately increases ethanol production. The $a d h E^{\mathrm{D} 494 \mathrm{G}}$ mutation is known to expand cofactor specificity of ADH reaction from NADH-only to either NADH or NADPH [28] thus the mutant adhE has access to both the NADH and NADPH pools, where previously it only had access to the NADH pool.
Finally, when cultured under industrially relevant levels of cellulose, strains that have undergone ALE can solubilize up to $109.2 \mathrm{~g}$ glucose equivalent/L cellulose, which represent an undiminished cellulolytic ability compared to wild-type C. thermocellum. Knocking out pathways for lactate and acetate make valine the second fermentation product after ethanol. An ALE-generated ldh-pta knockout strain of $C$. thermocellum with the $A d h E^{\mathrm{D} 4949 \mathrm{G}}$ mutation produced $29.9 \mathrm{~g} / \mathrm{L}$ ethanol and $5.1 \mathrm{~g} / \mathrm{L}$ isobutanol. This supports the hypothesis that a strain of $C$. thermocellum can be developed able to produce ethanol at high yield and still rapidly solubilize and utilize cellulose.

\section{Methods}

\section{Microbial strains}

Strains used in this study are listed in Table 2; strain lineages are also presented diagrammatically in "Results and discussion" section.

Methodological details for the development of strains via ALE are as follows: wild-type C. thermocellum strain DSM 1313 was originally obtained from the DSMZ culture collection. Strain LL374 was adapted from LL1044 by culturing in a pH auxostat for $500 \mathrm{~h}$. Strain LL375 was adapted from LL1044 by culturing in a chemostat for 500 h. Strain LL1011 was adapted from LL1042 by culturing in a pH auxostat. Strain LL1043 was adapted from LL1042 by 60 serial transfers with 1:100 dilution

Table 2 Strains used in this study

\begin{tabular}{|c|c|c|c|c|c|}
\hline Strain ID & Parent strain ID & $\begin{array}{l}\text { Alternate } \\
\text { designation }\end{array}$ & Genotype & $\begin{array}{l}\text { Sequence } \\
\text { data accession } \\
\text { number }\end{array}$ & References \\
\hline LL345 & LL1004 & M1354 & $\Delta h p t$ & SRP053786 & [8] \\
\hline LL372 & LL376 & M1629 & $\Delta h p t \triangle s p o 0 A \Delta / d h$ & SRP083692 & [9] \\
\hline LL373 & LL376 & M1630 & $\Delta h p t \triangle s p o 0 A \triangle p t a$ & SRP083691 & [9] \\
\hline LL374 & LL1044 & M1724 & $\begin{array}{l}\Delta h p t \Delta s p o 0 A \Delta l d h \triangle p t a:: P g a p D \text {-cat-hpt adapted by pH } \\
\quad \text { auxostat }\end{array}$ & SRP083690 & [62] \\
\hline LL375 & LL1044 & M1725 & $\begin{array}{l}\Delta \text { hpt } \triangle \text { spoOA } \triangle l d h \triangle \text { pta::PgapD-cat-hpt adapted by chemo- } \\
\text { stat }\end{array}$ & SRP083695 & [9] \\
\hline LL376 & LL345 & M1726 & $\triangle h p t \triangle s p o 0 A$ & SRP083697 & [9] \\
\hline LL1004 & & DSM1313 & Wt & SRP077312 & DSMZ culture collection \\
\hline LL1011 & LL1042 & & $\Delta h p t \Delta / d h \Delta p t a$ adapted by serial transfer & SRP054852 & {$[62]$} \\
\hline LL1036 & LL345 & M1407 & $\Delta h p t \Delta / d h$ & SRP054849 & {$[8]$} \\
\hline LL1041 & LL345 & M1448 & $\Delta h p t \Delta p t a$ & SRP054855 & [8] \\
\hline LL1042 & LL1036 & M1434 & $\Delta h p t \Delta l d h \Delta p t a$ & SRP054854 & [8] \\
\hline LL1043 & LL1042 & M1570 & $\begin{array}{l}\Delta h p t \Delta / d h \\
\Delta p t a:: P g a p D-c a t-h p t \text { adapted by } p H \text { auxostat }\end{array}$ & SRP053784 & [8] \\
\hline LL1044 & LL372 & M1655 & $\Delta h p t \Delta$ spoOA $\triangle l d h \triangle p t a:$ PgapD-cat-hpt & SRP077297 & [9] \\
\hline LL1111 & LL345 & & $\begin{array}{l}\Delta h p t l d h^{S 161 R} \\
\text { SadhE }\end{array}$ & SRP049310 & [11] \\
\hline LL1160 & LL1111 & & $\Delta h p t l d h^{S 161 R} \triangle a d h E:: a d h E$ & SRP059563 & {$[28]$} \\
\hline LL1161 & LL1111 & & $\Delta h p t l d h^{S 161 R} \Delta a d h E:: a d h E^{D 494 G}$ & SRP059562 & {$[28]$} \\
\hline
\end{tabular}


(approximately 200 generations). All strains in Table 2 except LL1111, LL1160 and LL1161 were originally developed by Mascoma Corporation. Strain construction is described in detail in the references in Table 2. All strains were conserved in the Lynd laboratory strain collection cultured on CTFUD [22] in $1 \mathrm{~mL}$ aliquots stored at $-80{ }^{\circ} \mathrm{C}$. For use in the experiments described here, freezer stocks of all strains were made on MTC medium (see "Growth media"). For each strain an overnight $50 \mathrm{~mL}$ working volume serum bottle culture was aliquoted into $5 \mathrm{~mL}$ volumes and stored at $-80^{\circ} \mathrm{C}$.

\section{Growth media}

Medium for thermophilic clostridia (MTC) was used for making freezer strain stocks and for cultivation on high cellulose loadings [13], and modified low-carbon medium (LCmed) used for microplate growth rate assays and carbon-limited chemostat cultivation [31].

For generating freezer stocks MTC contained $5 \mathrm{~g} / \mathrm{L}$ crystalline cellulose (Avicel ${ }^{\circledR}$ PH105) as carbon source, $5 \mathrm{~g} / \mathrm{L} 3-\mathrm{N}$-morpholino propanesulfonic acid (MOPS) for $\mathrm{pH}$ buffering and $2 \mathrm{~g} / \mathrm{L}$ urea $\left(\mathrm{CH}_{4} \mathrm{~N}_{2} \mathrm{O}\right)$ as nitrogen source; final concentrations: $5 \mathrm{~g} / \mathrm{L}$ cellulose $\left(\left[\mathrm{C}_{6} \mathrm{H}_{10} \mathrm{O}_{5}\right]_{\mathrm{x}}\right)$, $2.0 \mathrm{~g} / \mathrm{L}$ citric acid tripotassium salt $\left(\mathrm{C}_{6} \mathrm{H}_{5} \mathrm{O}_{7} \mathrm{~K}_{3}\right), 1.25 \mathrm{~g} / \mathrm{L}$ citric acid monohydrate $\left(\mathrm{C}_{6} \mathrm{H}_{5} \mathrm{O}_{7} \cdot \mathrm{H}_{2} \mathrm{O}\right), 1.0 \mathrm{~g} / \mathrm{L} \mathrm{Na}_{2} \mathrm{SO}_{4}$, $1.0 \mathrm{~g} / \mathrm{L} \mathrm{KH}_{2} \mathrm{PO}_{4}, 2.5 \mathrm{~g} / \mathrm{L} \mathrm{NaHCO} 3,1.0 \mathrm{~g} / \mathrm{L} \mathrm{MgCl}_{2} \cdot 6 \mathrm{H}_{2} \mathrm{O}$, $0.2 \mathrm{~g} / \mathrm{L} \quad \mathrm{CaCl}_{2} \cdot 2 \mathrm{H}_{2} \mathrm{O}, \quad 0.1 \mathrm{~g} / \mathrm{L} \quad \mathrm{FeCl}_{2} \cdot 4 \mathrm{H}_{2} \mathrm{O}, 1.0 \mathrm{~g} / \mathrm{L}$ L-cysteine $\mathrm{HCl} \cdot \mathrm{H}_{2} \mathrm{O}, 20 \mathrm{mg} / \mathrm{L}$ pyridoxamine dihydrochloride, $4 \mathrm{mg} / \mathrm{L}$ PABA, $2 \mathrm{mg} / \mathrm{L}$ D-biotin, $2 \mathrm{mg} / \mathrm{L} \mathrm{B}_{12}, 6 \mathrm{mg} / \mathrm{L}$ $\mathrm{MnCl}_{2} \cdot 4 \mathrm{H}_{2} \mathrm{O}, 2.5 \mathrm{mg} / \mathrm{L} \mathrm{ZnCl}, 0.6 \mathrm{mg} / \mathrm{L} \mathrm{CoCl} \cdot 6 \mathrm{H}_{2} \mathrm{O}$, $0.6 \mathrm{mg} / \mathrm{L} \mathrm{NiCl}_{2} \cdot 6 \mathrm{H}_{2} \mathrm{O}, 0.6 \mathrm{mg} / \mathrm{L} \mathrm{CuSO}_{4} \cdot 5 \mathrm{H}_{2} \mathrm{O}, 0.6 \mathrm{mg} / \mathrm{L}$ $\mathrm{H}_{3} \mathrm{BO}_{3}$ and $0.6 \mathrm{mg} / \mathrm{L} \mathrm{Na} \mathrm{MoO}_{4} \cdot 2 \mathrm{H}_{2} \mathrm{O}$.

For high cellulose loading cultivation in bioreactors MTC contained $120 \mathrm{~g} / \mathrm{L}$ crystalline cellulose as carbon source, no MOPS and $5 \mathrm{~g} / \mathrm{L}$ urea as nitrogen source. Vitamins and trace elements were increased with final concentrations at $80 \mathrm{mg} / \mathrm{L}$ pyridoxamine dihydrochloride, $16.0 \mathrm{mg} / \mathrm{L}$ para-aminobenzoic acid (PABA), $8 \mathrm{mg} / \mathrm{L}$ D-biotin and $18 \mathrm{mg} / \mathrm{L}$ vitamin $\mathrm{B}_{12}, 5.0 \mathrm{mg} / \mathrm{L} \mathrm{MnCl} 2 \cdot 4 \mathrm{H}_{2} \mathrm{O}$, $2.5 \mathrm{mg} / \mathrm{L} \mathrm{ZnCl} \cdot 6 \mathrm{H}_{2} \mathrm{O}, 0.5 \mathrm{mg} / \mathrm{L} \mathrm{CoCl} \mathrm{Co}_{2} \cdot 6 \mathrm{H}_{2} \mathrm{O}, 0.5 \mathrm{mg} / \mathrm{L}$ $\mathrm{NiCl}_{2} \cdot 6 \mathrm{H}_{2} \mathrm{O}, 0.5 \mathrm{mg} / \mathrm{L} \mathrm{CuSO}_{4} \cdot 5 \mathrm{H}_{2} \mathrm{O}, 0.5 \mathrm{mg} / \mathrm{L} \mathrm{H}_{3} \mathrm{BO}_{3}$ and $0.5 \mathrm{mg} / \mathrm{L} \mathrm{Na}_{2} \mathrm{MoO}_{4}$ ).

For cultivation in chemostats modified LCmed contained $5 \mathrm{~g} / \mathrm{L}$ cellobiose $\left(\mathrm{C}_{12} \mathrm{H}_{22} \mathrm{O}_{11}\right), 2.0 \mathrm{~g} / \mathrm{L} \mathrm{KH}_{2} \mathrm{PO}_{4}$, $3.0 \mathrm{~g} / \mathrm{L} \mathrm{K}_{2} \mathrm{HPO}_{4}, 0.1 \mathrm{~g} / \mathrm{L} \mathrm{Na}_{2} \mathrm{SO}_{4}, 0.5 \mathrm{~g} / \mathrm{L}$ urea $\left(\mathrm{CH}_{4} \mathrm{~N}_{2} \mathrm{O}\right)$, $0.2 \mathrm{~g} / \mathrm{L} \mathrm{MgCl}_{2} \cdot 6 \mathrm{H}_{2} \mathrm{O}, 0.05 \mathrm{~g} / \mathrm{L} \mathrm{CaCl} \cdot 2 \mathrm{H}_{2} \mathrm{O}, 0.0035 \mathrm{~g} / \mathrm{L}$ $\mathrm{FeSO}_{2} \cdot 7 \mathrm{H}_{2} \mathrm{O}, 0.025 \mathrm{~g} / \mathrm{L} \mathrm{FeCl}{ }_{2} \cdot 4 \mathrm{H}_{2} \mathrm{O}, 1.0 \mathrm{~g} / \mathrm{L}$ L-cysteine $\mathrm{HCl} \cdot \mathrm{H}_{2} \mathrm{O}, 20 \mathrm{mg} / \mathrm{L}$ pyridoxamine dihydrochloride, $4 \mathrm{mg} / \mathrm{L}$ PABA, $2 \mathrm{mg} / \mathrm{L}$ D-biotin, $2 \mathrm{mg} / \mathrm{L} \mathrm{B} \mathrm{B}_{12}, 6 \mathrm{mg} / \mathrm{L}$ $\mathrm{MnCl}_{2} \cdot 4 \mathrm{H}_{2} \mathrm{O}, 2.5 \mathrm{mg} / \mathrm{L} \mathrm{ZnCl}, 0.6 \mathrm{mg} / \mathrm{L} \mathrm{CoCl} \mathrm{Zn}_{2} \cdot 6 \mathrm{H}_{2} \mathrm{O}$, $0.6 \mathrm{mg} / \mathrm{L} \mathrm{NiCl} 2 \cdot 6 \mathrm{H}_{2} \mathrm{O}, 0.6 \mathrm{mg} / \mathrm{L} \mathrm{CuSO}_{4} \cdot 5 \mathrm{H}_{2} \mathrm{O}, 0.6 \mathrm{mg} / \mathrm{L}$ $\mathrm{H}_{3} \mathrm{BO}_{3}$ and $0.6 \mathrm{mg} / \mathrm{L} \mathrm{Na}_{2} \mathrm{MoO}_{4} \cdot 2 \mathrm{H}_{2} \mathrm{O}$. This medium was also used for the plate reader assays, but then complemented with $5 \mathrm{~g} / \mathrm{L}$ MOPS for $\mathrm{pH}$ buffering.

All media were prepared in 6 (bioreactor experiments) or 7 (bottle and plate reader experiments) separate solutions as indicated in Holwerda et al. [31].

\section{Growth rate analysis}

Growth rate and culture density (optical density at $600 \mathrm{~nm}$, i.e., $\mathrm{OD}_{600}$ ) were determined by measuring the $\mathrm{OD}_{600}$ every $3 \mathrm{~min}$ for cultures grown in a covered 96-well plate placed in a plate reader (BioTek, Winooski, VT). The plate reader was modified by the manufacturer to enable cultivation at $55{ }^{\circ} \mathrm{C}$, and measurements were based on $\geq$ triplicate cultivations on modified LC medium containing $5 \mathrm{~g} / \mathrm{L}$ cellobiose. The plate was automatically briefly shaken before recording every data point. All strains were cultured on modified LC medium before being used as inoculum. BioTek Gen5 microplate reader data analysis software enabled rate determination in the logarithmic range of growth.

\section{Fermentation products, cell biomass, amino acids and cellulose solubilization measurements}

The fermentation products acetate, lactate, formate, ethanol, 2,3-butanediol, isobutanol, fumarate, pyruvate, malate, pyroglutamate and the sugars glucose and cellobiose were measured by high performance liquid chromatography (HPLC, Waters, Milford, MA) using both refractive index and UV at 210 and $250 \mathrm{~nm}$ with an Aminex HPC-87H column (Bio-Rad Hercules, CA) as described in [13]. Pellet carbon and nitrogen as proxy for cellular biomass were measured on a Shimadzu TOCVcph total organic carbon analyzer with an additional total nitrogen unit (Shimadzu Scientific Instruments, Columbia MD). An acidified glycine solution was used as a standard for both carbon and nitrogen [63]. Residual cellulose for the high cellulose batch cultivations was determined by quantitative saccharification [64] as described in [13].

\section{Amino acids determination}

Free amino acids (alanine, arginine, asparagine, aspartic acid, glutamic acid, glutamine, histidine, isoleucine, leucine, lysine, methionine, phenylalanine, proline, serine, threonine, tryptophan, tyrosine, and valine) were determined from broth supernatant by mass spectrometry against a ${ }^{15} \mathrm{~N}$ labeled amino acid standard (Cell Free Amino Acids mix, Cambridge Isotope Laboratories, Tewksbury, MA), which were in turn quantified against purified non-labeled amino acids (Sigma-Aldrich, St. Louis, Mo). Samples were mixed with ${ }^{15} \mathrm{~N}$-labeled standards in varying ratios to give roughly equivalent final 
MS intensities for each amino acid (within 1/10 of each other). C. thermocellum broth supernatant (culture broth centrifuged at $21,130 \times g / 15,000 \mathrm{rpm}$ for $2-5 \mathrm{~min}$ and pellet removed) was diluted 1 in 10 in HPLC running buffer and analyzed by HPLC/MS. HPLC/MS conditions were as described in Tian et al. [65], generally injecting 10- $\mu$ l samples. Results were corrected for natural abundance of ${ }^{15} \mathrm{~N}$.

\section{Anthrone assay for residual supernatant carbohydrates}

Soluble carbohydrate present in the supernatant was quantified using the anthrone assay. Anthrone reagent (anthrone, water, sulfuric acid and ethanol) was added to supernatant aliquots in triplicates, mixed and heated to $100{ }^{\circ} \mathrm{C}$ for $20 \mathrm{~min}$. After color development, carbohydrates were measured versus a serial dilution of a glucose standard at $650 \mathrm{~nm}$ [66]. Glucose and cellobiose concentrations measured prior by HPLC were subtracted from the total to eliminate double counting.

\section{Hydrogen gas analysis}

The headspace of the chemostats was continuously purged with nitrogen gas at $5 \mathrm{~mL} / \mathrm{min}$, the off-gas was channeled through a detachable $150-\mathrm{mL}$ serum bottle stoppered with a butyl rubber stopper. At the time of sampling this bottle was disconnected from the off-gas stream and saved for gas analysis. The hydrogen gas concentration in the serum bottle was measured on a 310 Educational gas chromatograph (SRI Instruments, Torrence CA) with a HayeSep D packed column $\left(151{ }^{\circ} \mathrm{C}\right)$ and thermal conductivity detector against know standards with nitrogen as carrier gas $(8.2 \mathrm{~mL} / \mathrm{min})$. PeakSimple software (SRI Instruments, Torrence CA) aided in the determination of the hydrogen concentration in the off-gas.

\section{Bioreactor set-up and cultivation conditions}

The chemostat bioreactor set-up consisted of $0.5 \mathrm{~L}$ custom-built glass fermentation vessels (NDS Technologies, Vineland NJ) controlled by a Qplus multiplex cultivation system (Sartorius Stedim, Bohemia $\mathrm{NY}$ ) with a working volume of $300 \mathrm{~mL}$, maintained at $55^{\circ} \mathrm{C}$ by a $19.6 \mathrm{~L}$ Polystat external water bath (Cole Parmer, Vernon Hills Il). The headspace was continuously flushed with 'Ultrapure' nitrogen gas (Airgas, White River Junction VT) at $5 \mathrm{~mL} / \mathrm{min}$ to ensure a slight overpressure in the vessel headspace, the condenser was kept at $4-5{ }^{\circ} \mathrm{C}$ with a $6 \mathrm{~L}$ Polystat cooling bath (Cole Parmer, Vernon hills Il). Medium was supplied by continuous operation of a Watson-Marlow 205S peristaltic pump (Watson-Marlow, Wilmington MA). The effluent pump was automatically activated by level control; the level of the fermentation broth closed an electrical circuit, which activated the pump. The feed carboy and effluent vessels were placed on scales with accompanying software (A\&D company, San Jose, CA), data were collected every minute from which the dilution rate could be calculated with high accuracy. The $\mathrm{pH}$ level of the bioreactor was maintained at 7.0 by a gel-filled $\mathrm{pH}$ probe (Mettler-Toledo, Billerica, MA) and automated addition of $4 \mathrm{~N} \mathrm{KOH}$. Optical density in the near-infrared range (NIR) was monitored in situ by a DASGIP OD4 system at $850 \mathrm{~nm}$ (Dasgip Eppendorf, Hauppauge, NY) for each chemostat run which enabled closely monitoring of cellular biomass dynamics and determination of steady state. Each strain, except LL1111, was cultivated in duplicate in chemostats and each individual chemostat run was sampled twice; the first time after at least 4 residence times $(\geq 40 \mathrm{~h})$ and a second time after at least 7 residence times $(\geq 70 \mathrm{~h})$ from initiation of the continuous feed mode. The feed was started after culturing for $\sim 20 \mathrm{~h}$ in batch mode and was only initiated after the $\mathrm{OD}_{850}$ had reached a maximum. All strains (except LL1111) were grown in chemostats under carbon-limiting conditions at a dilution rate of $0.1 \mathrm{~h}^{-1}$.

High cellulose batch fermentations were carried out as described previously [13], but with $120 \mathrm{~g} / \mathrm{L}$ and without intermittent addition of vitamins. Cultivation conditions for high solids reactors were the same as with the chemostat cultivation, except the stirring rate was set $300 \mathrm{rpm}$, the working volume was $1 \mathrm{~L}$ and the medium used was MTC. Fermentations were sampled for at least 12 time points, and were stopped $220 \mathrm{~h}$ after inoculation by which point base addition and gas formation had ceased. Each of the end-strains tested at high solids was cultivated in duplicate. The rate of substrate solubilization was determined by fitting a sigmoidal curve to the average residual cellulose concentration of duplicate reactor runs as determined by quantitative saccharafication (QS) in gram glucose equivalents/L, each time point for each reactor run was assayed by QS in triplicate. The first derivate of the sigmoidal fit describes the rate of cellulose solubilization in gram glucose equivalents $/ \mathrm{L} / \mathrm{h}$; see also $[13,67]$.

\section{Genome resequencing}

Whole-genome sequencing was used to verify strain construction and check for secondary mutations. Raw data are available from the NCBI Sequence Read Archive (see accession numbers in Table 2). DNA was submitted to the Joint Genome Institute (JGI) for sequencing with an Illumina MiSeq, HiSeq 2000 or HiSeq 2500 instrument. Unamplified libraries were generated using a modified 
version of Illumina's standard protocol. $100 \mathrm{ng}$ of DNA was sheared to $500 \mathrm{bp}$ (or in some cases $4000 \mathrm{bp}$ ) using a focused ultrasonicator (Covaris). The sheared DNA fragments were size-selected using SPRI beads (Beckman Coulter). The selected fragments were then end-repaired, A-tailed, and ligated to Illumina compatible adapters (IDT, Inc.) using KAPA-Illumina library creation kit (KAPA biosystems). Libraries were quantified using KAPA Biosystems' next-generation sequencing library qPCR kit and run on a Roche LightCycler 480 real-time PCR instrument. The quantified libraries were then multiplexed into pools for sequencing. The pools were loaded and sequenced using the appropriate Illumina Reagent Kit for a $2 \times 100$ or $2 \times 150$ bp indexed run to generate paired-end reads. At the beginning, we collected 100bp reads. When the Illumina sequencing technology improved, we switched to 150-bp reads. An insert length of $500 \mathrm{bp}$ was used for routine sequencing. For some strains, we also used an insert length of $4000 \mathrm{bp}$ to allow repeat regions to be resolved.

Data were analyzed with CLC Genomics Workbench v10 (Qiagen, Germantown MD). First, sequences were trimmed for quality $(>0.001)$ and ambiguous residues (max of 1). Then 2,500,000 reads were sampled to give an average read depth of about 105 (for 100 bp reads, $3,750,000$ reads were sampled to maintain the same average read depth). Reads were mapped to the NC_017304.1 reference genome, using the default parameters, except that similarity fraction was increased from 0.8 to 0.95 to reduce mapping errors. The preliminary alignment was improved by 2 passes of local re-alignment. Mutations were identified using the "basic variant detection" and "structural variant" tools. Mutations were filtered against control reads from wt $C$. thermocellum (LL1004) to eliminate false-positive mutations due to differences between our laboratory strain of $C$. thermocellum and the reference genome.

\section{Mutation annotation}

Mutations were classified as "origin mutations" if the mutation was not present in the parent strain (i.e., inherited). For the purposes of correlating mutations with phenotypes, inherited mutations were ignored. To identify mutations in the regulatory region of a gene, we chose an arbitrary threshold of 500 bp upstream of the target gene. A mutation was considered an 'upstream mutation' if it was within $500 \mathrm{bp}$ upstream of the target gene and not part of another coding region.

\section{Gene expression analysis RNA preparation}

Samples for RNA were harvested from chemostats by spinning down duplicate $20 \mathrm{~mL}$ samples for $5 \mathrm{~min}$ at
$3500 \times g$ at $5{ }^{\circ} \mathrm{C}$ in a fixed angle refrigerated centrifuge immediately after sampling (Biofuge 15R, Heraeus, Germany). Supernatant was discarded, and pellets were flash frozen in liquid nitrogen and stored at $-80{ }^{\circ} \mathrm{C}$ upon RNA isolation. Upon extraction the pellet was treated with $20 \mathrm{~mL}$ of RNA Protect Bacteria Reagent (Qiagen). RNA was extracted by RNeasy mini kit (Qiagen) and contaminated DNA was removed using RNase-Free DNase set (Qiagen). The resulting RNA was quantified using a Qubit 2.0 fluorometer using Life Technologies Quant-iT ${ }^{\mathrm{TM}}$ RNA Assay Kit. The standard curve contained three points $(50 \mathrm{ng} / \mu \mathrm{L}, 400 \mathrm{ng} / \mu \mathrm{L}$, and $1000 \mathrm{ng} /$ $\mu \mathrm{L})$ and a blank. The quality was analyzed using the Agilent 2100 BioAnalyzer. RNA purity was determined with a NanoDrop spectrophotometer, by measuring the ratio of absorbance at $260 \mathrm{~nm}$ vs. $280 \mathrm{~nm}$.

\section{RNAseq analysis}

For RNAseq analysis, RNA (prepared as described in the "RNA preparation" section) was sent to the Joint Genome Institute (Walnut Creek, CA) for conversion to cDNA and Illumina sequencing. Ribosomal RNA (rRNA) was removed from $100 \mathrm{ng}$ of total RNA using Ribo-Zero (TM) rRNA Removal Kit (Epicentre). Stranded cDNA libraries were generated using the Illumina Truseq Stranded RNA LT kit. The rRNA depleted RNA was fragmented (500 bp approximate size) and reversed transcribed using random hexamers and SSII (Invitrogen) followed by second strand synthesis. The fragmented cDNA was treated with end-pair, A-tailing, adapter ligation, and 10 cycles of PCR. The prepared library was quantified using KAPA Biosystem's next-generation sequencing library qPCR kit and run on a Roche LightCycler 480 real-time PCR instrument. The quantified library was then pooled with other libraries and sequenced (see "Genome resequencing" section for details). For strains LL376, LL1044 and LL1042, one RNA prep was rejected due to low quality and no RNAseq data was generated for that sample, resulting in 3 rather than 4 replicates for those strains.

Data was normalized as follows: raw fastq file reads were filtered and trimmed using the JGI QC pipeline resulting in the filtered fastq file (".anqrptk.fastq.gz files). Using BBDuk (http://jgi.doe.gov/data-and-tools/ bbtools/bb-tools-user-guide/bbduk-guide/), raw reads were evaluated for artifact sequence by kmer matching $(\mathrm{kmer}=25)$, allowing 1 mismatch and detected artifact was trimmed from the $3^{\prime}$ end of the reads. RNA spikein reads, PhiX reads and reads containing any Ns were removed. Quality trimming was performed using the phred trimming method set at Q10. Following trimming, reads under the minimum length threshold of 45 bases were removed. Reads were mapped to the reference $C$. thermocellum genome (NC_017304.1). Gene expression 
was determined by normalizing the total number of reads for each library and then normalizing for gene length to get reads per kilobase per million mapped reads (RPKM). These data are presented in Additional files 7, 8 and 9: Table S7, Table S8 and Table S9.

Libraries BCHGZ (strain LL374) and BCGYG (LL372) showed a compressed dynamic range, which likely indicates problems with the library construction or sample processing, and these libraries were eliminated from the data. Thus, these strains have 3 rather than 4 replicates of expression data.

\section{Supplementary information}

Supplementary information accompanies this paper at https://doi. org/10.1186/s13068-020-01680-5.

\begin{abstract}
Additional file 1. Table S1: (A) Overview of cell biomass concentration, main fermentation products, hydrogen production, the cellobiose concentration in feed and the average dilution rate for each of the 15 strains. (B) Overview of all amino acids produced during fermentation for the 15 strains in milligram/Liter.
\end{abstract}

Additional file 2: Table S2. All mutations in all strains. Genes identified by Clostridium thermocellum locus number from Genbank NC_017304.1, which is also used for chromosomal coordinates of the start region of the mutation ("StartReg" column). For each mutation, the fraction of reads that support the mutation is given.

Additional file 3: Figure S3. Evidence for merodiploid arrangement of pta locus.

Additional file 4: Figure S4. Evidence for wild type arrangement of gapDH locus.

Additional file 5: Figure S5. Total number of mutations in each strain, identified by either DNA or RNA sequencing.

Additional file 6: Supplemental text S6. Discussion of convergent mutations not related to ethanol production.

Additional file 7: Table S7. JGl libraries. Table describing each chemostat where samples were sent for RNAseq analysis. The ID column can be used to match RNAseq data to fermentation data. The JGl library column can be used to match individual RNAseq data.

Additional file 8: Table S8. RNAseq expression data for each gene and library. Units of reads per kilobase per million mapped reads (RPKM). Genes are identified by Clostridium thermocellum locus number, from Genbank NC_017304.1. The linkage between libraries and strains is given in Additional file 7: Table S7.

Additional file 9: Table S9. RNAseq expression data for each gene and strain. Units of reads per kilobase per million mapped reads (RPKM), median value for each strain ( $n \geq 4)$. Genes are identified by Clostridium thermocellum locus number, from Genbank NC_017304.1 and NCBI Genelnfo identifier number. Strains are identified by LL number (Table 2).

Additional file 10: Figure S10. Differential gene expression.

Additional file 11: Table S11. Table S11 (A) Overview of the residual cellulose concentration, the cell biomass concentration, main fermentation products, and amino acids produced by the four end-strains ( LL374, LL375, LL1011 and LL1043) cultivated on $120 \mathrm{~g} / \mathrm{L}$ cellulose (Figure 7). (B) Overview of all amino acids produced during fermentation the four end-strains on $120 \mathrm{~g} / \mathrm{L}$ cellulose (Figure 7). (C) Carbon recovery for the four end-strains on $120 \mathrm{~g} / \mathrm{L}$ cellulose (Figure 7 ).

\section{Abbreviations}

ALE: Adaptive laboratory evolution; pta: Phosphotransacetylase; adhE: Alcohol and aldehyde dehydrogenase E; hfsB: Hydrogenase-Fe-S B; Idh: Lactate dehydrogenase; $8 \mathrm{AZH}$ : 8-Azahypoxanthine; D: Dilution rate $\left(\mathrm{h}^{-1}\right)$; FBP: Fructose 1,6-bisphosphate; ack: Acetate kinase.

\section{Acknowledgements}

Sequencing was done in collaboration with the Joint Genome Institute (JGI) and the authors would like to thank Christa Pennacchio and colleagues at JGI for their assistance with this process.

The authors would like to thank Dr. Johannes (Hans) P. van Dijken, Professor Emeritus for his advice, particularly with respect to chemostat cultivation.

\section{Authors' contributions}

EKH designed, performed and analyzed all experiments. NMR assisted in the high solids fermentations. DMS and DAN measured secreted amino acids and analyzed data and provided input on the manuscript. MIM and AAL extracted and isolated RNA. SJLM performed GC analysis measuring hydrogen gas. EKH, MIM and DGO performed the growth rate assays. DGO analyzed RNAseq and genomic sequencing data. EKH, DGO and LRL wrote the manuscript. NMR has since moved to the Kingswood-Oxford School, West Hartford, CT. SJLM has since moved to the Department of Microbiology at Cornell University, Ithaca, NY. All authors read and approved the final manuscript.

\section{Funding}

Funding provided by The BioEnergy Science Center and The Center for Bioenergy Innovation both U.S. Department of Energy Research Centers supported by the Office of Biological and Environmental Research in the DOE Office of Science.

Sequencing was done in collaboration with the Joint Genome Institute (JGI). The Joint Genome Institute, a DOE Office of Science User Facility, is supported by the Office of Science of the U.S. Department of Energy under Contract No. DE-AC02-05CH11231.

\section{Availability of data and materials}

All data generated or analyzed during this study are included in this published article and its additional files. DNA sequences and resequencing results are available from GenBank via their accession numbers.

\section{Ethics approval and consent to participate}

Not applicable.

\section{Consent for publication}

Not applicable.

\section{Competing interests}

LRL is a shareholder in a start-up company focusing on cellulosic biofuel production and conversion. There are no other competing interests.

\section{Author details}

${ }^{1}$ Thayer School of Engineering, Dartmouth College, Hanover, NH 03755, USA. ${ }^{2}$ Department of Bacteriology, University of Wisconsin, Madison, WI 53706, USA. ${ }^{3}$ The Center for Bioenergy Innovation, Oak Ridge National Laboratory, Oak Ridge, TN 37831, USA.

Received: 12 June 2019 Accepted: 10 February 2020 Published online: 10 March 2020

\section{References}

1. Nielsen J, Keasling JD. Engineering cellular metabolism. Cell. 2016;164:1185-97. https://doi.org/10.1016/j.cell.2016.02.004.

2. Resch MG, Donohoe BS, Baker JO, Decker SR, Bayer EA, Beckham GT, et al. Fungal cellulases and complexed cellulosomal enzymes exhibit synergistic mechanisms in cellulose deconstruction. Energy Environ Sci. 2013;6:1858. https://doi.org/10.1039/c3ee00019b.

3. Paye JMD, Guseva A, Hammer SK, Gjersing E, Davis MF, Davison BH, et al. Biological lignocellulose solubilization: comparative evaluation of biocatalysts and enhancement via cotreatment. Biotechnol Biofuels. 2016;9:8. https://doi.org/10.1186/s13068-015-0412-y.

4. Holwerda EK, Worthen RS, Kothari N, Lasky RC, Davison BH, Fu C, et al. Multiple levers for overcoming the recalcitrance of lignocellulosic 
biomass. Biotechnol Biofuels. 2019;12:1-12. https://doi.org/10.1186/ s13068-019-1353-7.

5. Olson DG, Sparling R, Lynd LR. Ethanol production by engineered thermophiles. Curr Opin Biotechnol. 2015;33:130-41. https://doi. org/10.1016/j.copbio.2015.02.006.

6. Shawa J, Podkaminer KK, Desai SG, Bardsley JS, Rogers SR, Thorne PG, et al. Metabolic engineering of a thermophilic bacterium to produce ethanol at high yield. Proc Natl Acad Sci USA. 2008;105:13769-74. https:// doi.org/10.1073/pnas.0801266105.

7. Herring CD, Kenealy WR, Shaw AJ, Raman B, Tschaplinski TJ, Brown SD, Davison BH, et al. Final report on development of Thermoanaerobacterium saccharolyticum for the conversion of lignocellulose to ethanol. United States Department of Energy; 2012. p. 1-17. https://doi. org/10.2172/1033560.

8. Argyros DA, Tripathi SA, Barrett TF, Rogers SR, Feinberg LF, Olson DG, et al. High ethanol titers from cellulose by using metabolically engineered thermophilic, anaerobic microbes. Appl Environ Microbiol. 2011;77:828894. https://doi.org/10.1128/aem.00646-11.

9. van der Veen D, Lo J, Brown SD, Johnson CM, Tschaplinski TJ, Martin M, et al. Characterization of Clostridium thermocellum strains with disrupted fermentation end-product pathways. J Ind Microbiol Biotechnol. 2013:40:725-34

10. Mearls $E B$, Lynd LR. The identification of four histidine kinases that influence sporulation in Clostridium thermocellum. Anaerobe. 2014;28:109-19.

11. Lo J, Zheng T, Hon S, Olson DG, Lynd LR. The bifunctional alcohol and aldehyde dehydrogenase gene, $a d h E$, is necessary for ethanol production in Clostridium thermocellum and Thermoanaerobacterium saccharolyticum. J Bacteriol. 2015;197:1386-93.

12. Ellis LD, Holwerda EK, Hogsett D, Rogers S, Shao X, Tschaplinski T, et al. Closing the carbon balance for fermentation by Clostridium thermocellum (ATCC 27405). Bioresour Technol. 2012;103:293-9. https://doi. org/10.1016/j.biortech.2011.09.128.

13. Holwerda EK, Thorne PG, Olson DG, Amador-Noguez D, Engle NL, Tschaplinski TJ, et al. The exometabolome of Clostridium thermocellum reveals overflow metabolism at high cellulose loading. Biotechnol Biofuels. 2014:7:155. https://doi.org/10.1186/s13068-014-0155-1.

14. Thompson RA. Overflow metabolism and growth cessation in Clostridium thermocellum DSM1313 during high cellulose loading fermentations. Biotechnol Bioeng. 2017;114:2592-604.

15. Hon S, Olson DG, Holwerda EK, Lanahan AA, Murphy SJL, Maloney MI, et al. The ethanol pathway from Thermoanaerobacterium saccharolyticum improves ethanol production in Clostridium thermocellum. Metab Eng 2017:42:175-84. https://doi.org/10.1016/j.ymben.2017.06.011.

16. Weimer PJ, Zeikus JG. Fermentation of cellulose and cellobiose by Clostridium thermocellum in the absence and presence of Methanobacterium thermoautotrophicum. Appl Environ Microbiol. 1977;33:289-97.

17. Rydzak T, Levin DB, Cicek N, Sparling R. End-product induced metabolic shifts in Clostridium thermocellum ATCC 27405. Appl Microbiol Biotechnol. 2011:92:199-209.

18. Lamed RJ, Lobos JH, Su TM. Effects of stirring and hydrogen on fermentation products of Clostridium thermocellum. Appl Environ Microbiol. 1988;54:1216-21.

19. Li Q, Liu C-Z. Co-culture of Clostridium thermocellum and Clostridium thermosaccharolyticum for enhancing hydrogen production via thermophilic fermentation of cornstalk waste. Int J Hydrogen Energy. 2012;37:1064854. https://doi.org/10.1016/j.ijhydene.2012.04.115.

20. Bothun GD, Knutson BL, Berberich JA, Strobel HJ, Nokes SE. Metabolic selectivity and growth of Clostridium thermocellum in continuous culture under elevated hydrostatic pressure. Appl Microbiol Biotechnol. 2004;65:149-57. https://doi.org/10.1007/s00253-004-1554-1.

21. Biswas $R$, Zheng $T$, Olson DG, Lynd LR, Guss AM. Elimination of hydrogenase active site assembly blocks $\mathrm{H} 2$ production and increases ethanol yield in Clostridium thermocellum. Biotechnol Biofuels. 2015. https://doi. org/10.1186/s13068-015-0204-4

22. Olson DG, Lynd LR. Transformation of Clostridium thermocellum by electroporation. Methods Enzymol. 2012;510:317-30

23. Brown SD, Guss AM, Karpinets TV, Parks JM, Smolin N, Yang S, et al. Mutant alcohol dehydrogenase leads to improved ethanol tolerance in Clostridium thermocellum. Proc Natl Acad Sci USA. 2011;108:13752-7. https://doi.org/10.1073/pnas.1102444108.
24. Shao XJ, Raman B, Zhu MJ, Mielenz JR, Brown SD, Guss AM, et al. Mutant selection and phenotypic and genetic characterization of ethanoltolerant strains of Clostridium thermocellum. Appl Microbiol Biotechnol. 2011;92:641-52. https://doi.org/10.1007/s00253-011-3492-z.

25. Sevastopoulos C, Glaser D. Mutator action by Escherichia coli strains carrying dnaE mutations. Proc Natl Acad Sci. 1977;74:3947-50.

26. Vandewiele D, Fernández de Henestrosa AR, Timms AR, Bridges BA, Woodgate R. Sequence analysis and phenotypes of five temperature sensitive mutator alleles of dnaE, encoding modified a-catalytic subunits of Escherichia coli DNA polymerase III holoenzyme. Mutat Res Fundam Mol Mech Mutagen. 2002;499:85-95.

27. Eminoğlu A, Murphy SJ-L, Maloney M, Lanahan A, Giannone RJ, Hettich $\mathrm{RL}$, et al. Deletion of the $\mathrm{hfs} B$ gene increases ethanol production in Thermoanaerobacterium saccharolyticum and several other thermophilic anaerobic bacteria. Biotechnol Biofuels. 2017;10:282.

28. Zheng T, Olson DG, Tian L, Bomble YJ, Himmel ME, Lo J, et al. Cofactor specificity of the bifunctional alcohol and aldehyde dehydrogenase (AdhE) in wild-type and mutant Clostridium thermocellum and Thermoanaerobacterium saccharolyticum. J Bacteriol. 2015;197:2610-9.

29. Hon S, Lanahan AA, Tian L, Giannone RJ, Hettich RL, Olson DG, et al. Development of a plasmid-based expression system in Clostridium thermocellum and its use to screen heterologous expression of bifunctional alcohol dehydrogenases (adhEs). Metab Eng Commun. 2016:3:120-9.

30. Shaw AJ, Miller BB, Rogers SR, Kenealy WR, Meola A, Bhandiwad A, et al. Anaerobic detoxification of acetic acid in a thermophilic ethanologen. Biotechnol Biofuels. 2015;8:75.

31. Holwerda EK, Hirst KD, Lynd LR. A defined growth medium with very low background carbon for culturing Clostridium thermocellum. J Ind Microbiol Biotechnol. 2012;39:943-7. https://doi.org/10.1007/s1029 5-012-1091-3.

32. Papanek B, Biswas R, Rydzak T, Guss AM. Elimination of metabolic pathways to all traditional fermentation products increases ethanol yields in Clostridium thermocellum. Metab Eng. 2015;32:49-54. https:// doi.org/10.1016/j.ymben.2015.09.002.

33. Tian L, Papanek B, Olson DG, Rydzak T, Holwerda EK, Zheng T, et al. Simultaneous achievement of high ethanol yield and titer in Clostridium thermocellum. Biotechnol Biofuels. 2016:9:1-11.

34. Deng Y, Olson DG, Zhou J, Herring CD, Joe Shaw A, Lynd LR. Redirecting carbon flux through exogenous pyruvate kinase to achieve high ethanol yields in Clostridium thermocellum. Metab Eng. 2013;15:151-8. https://doi.org/10.1016/j.ymben.2012.11.006

35. Airaudo CB, Gayte-Sorbier A, Armand P. Stability of glutamine and pyroglutamic acid under model system conditions: influence of physical and technological factors. J Food Sci. 1987;52:1750-2. https://doi. org/10.1111/j.1365-2621.1987.tb05926.x.

36. Kumar A, Bachhawat AK. Pyroglutamic acid: throwing light on a lightly studied metabolite. Curr Sci. 2012;102:288-97.

37. Rydzak T, Garcia D, Stevenson DM, Sladek M, Klingeman DM, Holwerda EK, et al. Deletion of Type I glutamine synthetase deregulates nitrogen metabolism and increases ethanol production in Clostridium thermocellum. Metab Eng. 2017;41:182-91. https://doi.org/10.1016/j. ymben.2017.04.002.

38. Lin PP, Mi L, Morioka AH, Yoshino KM, Konishi S, Xu SC, et al. Consolidated bioprocessing of cellulose to isobutanol using Clostridium thermocellum. Metab Eng. 2015;31:44-52. https://doi.org/10.1016/j. ymben.2015.07.001.

39. Hon S, Holwerda EK, Worthen RS, Maloney MI, Tian L, Cui J, et al. Expressing the Thermoanaerobacterium saccharolyticum pforA in engineered Clostridium thermocellum improves ethanol production. Biotechnol Biofuels. 2018;in review:1-11. https://doi.org/10.1186/s1306 8-018-1245-2.

40. Guedon E. Improvement of cellulolytic properties of Clostridium celluloIyticum by metabolic engineering. Appl Environ Microbiol. 2002;68:538. https://doi.org/10.1128/AEM.68.1.53.

41. Li Y, Tschaplinski TJ, Engle NL, Hamilton CY, Rodriquez M, Liao JC, et al. Combined inactivation of the Clostridium cellulolyticum lactate and malate dehydrogenase genes substantially increases ethanol yield from cellulose and switchgrass fermentations. Biotechnol Biofuels. 2012;5:2. https://doi.org/10.1186/1754-6834-5-2. 
42. Tolonen AC, Zuroff TR, Ramya M, Boutard M, Cerisy T, Curtis WR. Physiology, genomics, and pathway engineering of an ethanoltolerant strain of Clostridium phytofermentans. Appl Environ Microbiol. 2015;81:5440-8.

43. Chung D, Cha M, Guss AM, Westpheling J. Direct conversion of plant biomass to ethanol by engineered Caldicellulosiruptor bescii. Proc Natl Acad Sci USA. 2014;111:8931-6.

44. Higashide W, Li Y, Yang Y, Liao JC. Metabolic engineering of Clostridium cellulolyticum for production of isobutanol from cellulose. Appl Environ Microbiol. 2011;77:2727-33. https://doi.org/10.1128/AEM.02454-10.

45. Li S, Huang D, Li Y, Wen J, Jia X. Rational improvement of the engineered isobutanol-producing Bacillus subtilis by elementary mode analysis. Microb Cell Fact. 2012;11:101. https://doi. org/10.1186/1475-2859-11-101.

46. Gaida SM, Liedtke A, Jentges AHW, Engels B, Jennewein S. Metabolic engineering of Clostridium cellulolyticum for the production of n-butanol from crystalline cellulose. Microb Cell Fact. 2016;15:1-11.

47. Yang X, Xu M, Yang ST. Metabolic and process engineering of Clostridium cellulovorans for biofuel production from cellulose. Metab Eng. 2015:32:39-48. https://doi.org/10.1016/j.ymben.2015.09.001.

48. Ou J, Xu N, Ernst P, Ma C, Bush M, Goh KY, et al. Process engineering of cellulosic $n$-butanol production from corn-based biomass using Clostridium cellulovorans. Process Biochem. 2017;62:144-50. https://doi. org/10.1016/j.procbio.2017.07.009.

49. Wen Z, Ledesma-amaro R, Lin J, Jiang Y. Improved n-butanol production from Clostridium cellulovorans by integrated metabolic and evolutionary engineering. Appl Environ Microbiol. 2019;85:1-17.

50. Bao T, Zhao J, Li J, Liu X, Yang ST. n-Butanol and ethanol production from cellulose by Clostridium cellulovorans overexpressing heterologous aldehyde/alcohol dehydrogenases. Bioresour Technol. 2019:285:121316. https://doi.org/10.1016/j.biortech.2019.121316.

51. Lee JH, Wendisch VF. Production of amino acids - genetic and metabolic engineering approaches. Bioresour Technol. 2017;245:1575-87. https://doi.org/10.1016/j.biortech.2017.05.065.

52. Becker J, Zelder O, Häfner S, Schröder H, Wittmann C. From zero to hero-design-based systems metabolic engineering of Corynebacterium glutamicum for L-lysine production. Metab Eng. 2011;13:159-68.

53. Mahr R, Gätgens C, Gätgens J, Polen T, Kalinowski J, Frunzke J. Biosensor-driven adaptive laboratory evolution of L-valine production in Corynebacterium glutamicum. Metab Eng. 2015;32:184-94. https:// doi.org/10.1016/j.ymben.2015.09.017.

54. Lee J, Saddler JN, Um Y, Woo HM. Adaptive evolution and metabolic engineering of a cellobiose- and xylose-negative Corynebacterium glutamicum that co-utilizes cellobiose and xylose. Microb Cell Fact. 2016;15:1-16.

55. Radek A, Tenhaef N, Müller MF, Brüsseler C, Wiechert W, Marienhagen J, et al. Miniaturized and automated adaptive laboratory evolution: evolving Corynebacterium glutamicum towards an improved D-xylose utilization. Bioresour Technol. 2017;245:1377-85. https://doi. org/10.1016/j.biortech.2017.05.055
56. Zhang B, Yu M, Zhou Y, Li Y, Ye BC. Systematic pathway engineering of Corynebacterium glutamicum 59114 for L-ornithine production. Microb Cell Fact. 2017:16:1-10.

57. Wen J, Bao J. Engineering Corynebacterium glutamicum triggers glutamic acid accumulation in biotin-rich corn stover hydrolysate. Biotechnol Biofuels. 2019;12:1-11. https://doi.org/10.1186/s1306 8-019-1428-5.

58. Becker J, Wittmann C. Bio-based production of chemicals, materials and fuels-Corynebacterium glutamicum as versatile cell factory. Curr Opin Biotechnol. 2012;23:631-40. https://doi.org/10.1016/j.copbi o.2011.11.012.

59. Kallscheuer N, Marienhagen J. Corynebacterium glutamicum as platform for the production of hydroxybenzoic acids. Microb Cell Fact. 2018;17:1-13. https://doi.org/10.1186/s12934-018-0923-x.

60. Olson DG, McBride JE, Shaw AJ, Lynd LR. Recent progress in consolidated bioprocessing. Curr Opin Biotechnol. 2012;23:396-405. https:// doi.org/10.1016/j.copbio.2011.11.026

61. Herring CD, Kenealy WR, Joe Shaw A, Covalla SF, Olson DG, Zhang J, et al. Strain and bioprocess improvement of a thermophilic anaerobe for the production of ethanol from wood. Biotechnol Biofuels. 2016;9:1-16.

62. Beri D, Olson DG, Holwerda EK, Lynd LR. Nicotinamide cofactor ratios in engineered strains of Clostridium thermocellum and Thermoanaerobacterium saccharolyticum. FEMS Microbiol Lett. 2016;363:fnw091.

63. Holwerda EK, Ellis LD, Lynd LR. Development and evaluation of methods to infer biosynthesis and substrate consumption in cultures of cellulolytic microorganisms. Biotechnol Bioeng. 2013;110:2380-8. https ://doi.org/10.1002/bit.24915.

64. Sluiter A, Hames B, Ruiz R, Scarlata C, Sluiter J, Templeton D, et al. Determination of structural carbohydrates and lignin in biomass determination of structural carbohydrates and lignin in biomass. 2010.

65. Tian L, Perot SJ, Stevenson D, Jacobson T, Lanahan AA, Amador-Noguez D, et al. Metabolome analysis reveals a role for glyceraldehyde 3-phosphate dehydrogenase in the inhibition of $C$. thermocellum by ethanol. Biotechnol Biofuels. 2017;10:1-11.

66. Hogsett DAL. Cellulose hydrolysis and fermentation by Clostridium thermocellum for the production of ethanol. Hanover: Dartmouth College; 1995.

67. Holwerda EK, Lynd LR. Testing alternative kinetic models for utilization of crystalline cellulose (Avicel) by batch cultures of Clostridium thermocellum. Biotechnol Bioeng. 2013;1 10:2389-94. https://doi.org/10.1002/ bit.24914.

\section{Publisher's Note}

Springer Nature remains neutral with regard to jurisdictional claims in published maps and institutional affiliations.

Ready to submit your research? Choose BMC and benefit from

- fast, convenient online submission

- thorough peer review by experienced researchers in your field

- rapid publication on acceptance

- support for research data, including large and complex data types

- gold Open Access which fosters wider collaboration and increased citations

- maximum visibility for your research: over 100M website views per year

At BMC, research is always in progress.

Learn more biomedcentral.com/submissions 